\title{
Application of short-term inhalation studies to assess the inhalation toxicity of nanomaterials
}

\author{
Robert Landsiedel ${ }^{1 *}$, Lan Ma-Hock ${ }^{1 \dagger}$, Thomas Hofmann ${ }^{1}$, Martin Wiemann², Volker Strauss $^{1}$, Silke Treumann , \\ Wendel Wohlleben ${ }^{1,3}$, Sibylle Gröters ${ }^{1}$, Karin Wiench ${ }^{4}$ and Bennard van Ravenzwaay ${ }^{1}$
}

\begin{abstract}
Background: A standard short-term inhalation study (STIS) was applied for hazard assessment of 13 metal oxide nanomaterials and micron-scale zinc oxide.

Methods: Rats were exposed to test material aerosols (ranging from 0.5 to $50 \mathrm{mg} / \mathrm{m}^{3}$ ) for five consecutive days with 14- or 21-day post-exposure observation. Bronchoalveolar lavage fluid (BALF) and histopathological sections of the entire respiratory tract were examined. Pulmonary deposition and clearance and test material translocation into extra-pulmonary organs were assessed.

Results: Inhaled nanomaterials were found in the lung, in alveolar macrophages, and in the draining lymph nodes. Polyacrylate-coated silica was also found in the spleen, and both zinc oxides elicited olfactory epithelium necrosis. None of the other nanomaterials was recorded in extra-pulmonary organs. Eight nanomaterials did not elicit pulmonary effects, and their no observed adverse effect concentrations (NOAECs) were at least $10 \mathrm{mg} / \mathrm{m}^{3}$. Five materials (coated nano- $\mathrm{TiO}_{2}$, both $\mathrm{ZnO}$, both $\mathrm{CeO}_{2}$ ) evoked concentration-dependent transient pulmonary inflammation. Most effects were at least partially reversible during the post-exposure period. Based on the NOAECs that were derived from quantitative parameters, with BALF polymorphonuclear (PMN) neutrophil counts and total protein concentration being most sensitive, or from the severity of histopathological findings, the materials were ranked by increasing toxic potency into 3 grades: lower toxic potency: $\mathrm{BaSO}_{4} ; \mathrm{SiO}_{2}$. acrylate (by local NOAEC); $\mathrm{SiO}_{2}$.PEG; $\mathrm{SiO}_{2}$.phosphate; $\mathrm{SiO}_{2}$.amino; nano- $\mathrm{ZrO}_{2} ; \mathrm{ZrO}_{2}$. TODA; $\mathrm{ZrO}_{2}$.acrylate; medium toxic potency: $\mathrm{SiO}_{2}$.naked; higher toxic potency: coated nano- $\mathrm{TiO}_{2}$; nano- $\mathrm{CeO}_{2} ; \mathrm{Al}$-doped nano- $\mathrm{CeO}_{2}$; micron-scale $\mathrm{ZnO}$; coated nano- $\mathrm{ZnO}$ (and $\mathrm{SiO}_{2}$.acrylate by systemic no observed effect concentration (NOEC)).

Conclusion: The STIS revealed the type of effects of 13 nanomaterials, and micron-scale $\mathrm{ZnO}$, information on their toxic potency, and the location and reversibility of effects. Assessment of lung burden and material translocation provided preliminary biokinetic information. Based upon the study results, the STIS protocol was re-assessed and preliminary suggestions regarding the grouping of nanomaterials for safety assessment were spelled out.
\end{abstract}

Keywords: Inhalation, Nanomaterial, $\mathrm{TiO}_{2}, \mathrm{ZnO}, \mathrm{SiO}_{2}, \mathrm{BaSO}_{4}, \mathrm{ZrO}_{2}, \mathrm{CeO}_{2}$, Rat, Bronchoalveolar lavage, Cytokine/ chemokine, Respiratory tract histopathology

\footnotetext{
* Correspondence: robert.landsiedel@basf.com

${ }^{\dagger}$ Equal contributors

'Experimental Toxicology and Ecology, BASF SE, 67056 Ludwigshafen, Germany

Full list of author information is available at the end of the article
}

\section{Ciomed Central}

(c) 2014 Landsiedel et al.; licensee BioMed Central Ltd. This is an Open Access article distributed under the terms of the Creative Commons Attribution License (http://creativecommons.org/licenses/by/2.0), which permits unrestricted use, distribution, and reproduction in any medium, provided the original work is properly credited. The Creative Commons Public Domain Dedication waiver (http://creativecommons.org/publicdomain/zero/1.0/) applies to the data made available in this article, unless otherwise stated. 


\section{Background}

Nanomaterials offer unique mechanical, chemical, electrical or optical properties that are being exploited for a broad spectrum of applications, including a variety of industrial and consumer products and products and devices in the medical field. However, the increased use of nanomaterials has also raised concerns about undesirable human health effects, especially upon inhalation uptake. Information on possible toxic effects of nanomaterials is essential to ensure occupational and consumer safety. Standard toxicological testing methods, such as the 90-day rodent inhalation study, have been recognized as generally being applicable in meeting this request. However, such studies are considerably timeconsuming and cost-intensive and not suitable for screening purposes or for the testing of larger numbers of compounds.

In addressing these drawbacks of long-term studies, a rat short-term inhalation study protocol (STIS) was developed within the project NanoCare (http://www.ptj.de/ nanocare; of note: all websites were accessed in March 2014) supported by the German Federal Ministry of Education and Research and the European Sixth Framework Programme project NanoSafe2 (www.nanosafe. org). The STIS protocol takes into account the specific properties of nanomaterials and encompasses a 5-day inhalation exposure period with a subsequent 3-week post-exposure period. During a first validation of this protocol, nano- $\mathrm{TiO}_{2}$ was applied as a model substance [1], and its effects were compared to micron-scale $\mathrm{TiO}_{2}$ and micron-scale quartz. The results of this initial study with $\mathrm{TiO}_{2}$ stood in good agreement with those obtained in a subchronic 90-day study [2].

The study at hand presents STIS data for nanomaterials, which were tested either during product development, i.e. $\mathrm{TiO}_{2}\left(\mathrm{~T}\right.$-lite $\left.\mathrm{SF}^{\mathrm{rM}}\right)$ and $\mathrm{ZnO}(\mathrm{NM}-111)$, or in the context of research projects, i.e. nano- $\mathrm{CeO}_{2}, \mathrm{Al}$-doped nano- $\mathrm{CeO}_{2}$, $\mathrm{ZrO}_{2}$ (with or without surface modifications), naked amorphous silica and four types of surface-coated silica, and $\mathrm{BaSO}_{4}$ (NM-220). Of note, NM-x numberings refer to the respective numberings of OECD reference nanomaterials, as they have been coded in the list of the OECD WPMN Sponsorship Program for the Testing of Manufactured Nanomaterials (http://www.oecd.org/ science/nanosafety/ and http://ihcp.jrc.ec.europa.eu/our_ activities/nanotechnology/nanomaterials-repository).

The STIS for both $\mathrm{CeO}_{2}$ nanomaterials and the $\mathrm{ZrO}_{2}$ without surface modification were performed in the context of the above-mentioned NanoCare project, and the STIS for the surface-functionalized $\mathrm{ZrO}_{2}$, all $\mathrm{SiO}_{2}$ materials and $\mathrm{BaSo}_{4}$ were conducted as a part of the 'nanoGEM' project (Nanostrukturierte Materialien Gesundheit, Exposition und Materialeigenschaften 'Nanostructured Materials - Health, Exposure and Material
Characteristics'; www.nanogem.de) funded by the German Federal Ministry of Education and Research. For a few of the test materials of the present study, data from chronic and subchronic studies are already available, and a comparison of the results from short-term versus long-term studies has recently been published [3], revealing consistent results regardless of the differing exposure periods.

Coated nano- $\mathrm{TiO}_{2}$ is being used as a sunscreen in cosmetic products. Nanosized $\mathrm{TiO}_{2}$ has been observed to elicit inflammatory effects [4-6] and morphological changes in the lung [2,7].

Just as $\mathrm{TiO}_{2}$, ZnO nanomaterials are used as UV absorbers. In workers, 'metal fume fever' effects caused by $\mathrm{ZnO}$ have been observed to be potent, but transient; in vitro, $\mathrm{ZnO}$ nanomaterials have been recorded to be highly toxic to many types of cells with concordant effects observed in vivo upon instillation, to the lung tissue [8]. Already at a bolus concentration of $0.3 \mathrm{mg}$ instilled into the rat lung, $\mathrm{ZnO}$ nanoparticles induced collagen formation 4 weeks post-instillation [9]. This lung burden can be achieved by 4-week inhalation exposure to $2 \mathrm{mg} / \mathrm{m}^{3}$ ( $6 \mathrm{~h} /$ day, 5 days/week), assuming $10 \%$ deposition and the clearance rate of a poorly soluble particle. $\mathrm{ZnO}$ particles selected for the present study were a coated nano- $\mathrm{ZnO}$ (OECD NM-111) and a micron-scale, uncoated $\mathrm{ZnO}$.

Synthetic naked amorphous silica can be subdivided into wet process-manufactured (precipitated) silica and pyrogenic silica. The surface of silica particles can additionally be coated with a variety of organic materials (overview in [10]). Synthetic amorphous silica particles are being used as filling materials in plastics, lacquers, paints and tyres but also in pharmaceuticals, cosmetics, and foods. In contrast to crystalline silica, the biological effects of synthetic naked amorphous silicas appear to be transient and, depending on the concentration, reversible [10-12]. Precipitated uncoated amorphous silica (in the following: $\mathrm{SiO}_{2}$. naked) and four surface modifications thereof $\left(\mathrm{SiO}_{2}\right.$.polyacrylate, $\mathrm{SiO}_{2}$.polyethyleneglycol $\left(\mathrm{SiO}_{2} \cdot \mathrm{PEG}\right), \mathrm{SiO}_{2}$. phosphate, $\mathrm{SiO}_{2}$.amino) were tested in the present study.

Nanosized $\mathrm{BaSO}_{4}$ is being used as a filling material in polymer compositions to increase scratch resistance while conserving transparency. Upon inhalation, micron-scale $\mathrm{BaSO}_{4}$ only induces very slight transient inflammatory reactions [13], and it has been used for a long time as a radio-contrast agent for medical diagnostic purposes. By contrast, nanosized $\mathrm{BaSO}_{4}$ particles have a much larger surface area and have not yet been tested via the inhalation route.

Industrial areas of use of $\mathrm{ZrO}_{2}$ particles include applications in foundry sands, refractories, and ceramics. The material is also used for the coating of hip joint endoprostheses or dental prostheses. $\mathrm{ZrO}_{2}$ particles increase 
durability and scratch resistance of enamels and varnishes. Micron-scale $\mathrm{ZrO}_{2}$, as investigated by Pott and Roller [14], possesses a comparatively low carcinogenic potential under severe overload conditions achieved by intratracheal instillation of bolus doses of $60 \mathrm{mg} / \mathrm{rat}$ lung. So far, there are no data available on the pulmonary effects of nano- $\mathrm{ZrO}_{2}$ particles either without or with surface modification. Hence the nano- $\mathrm{ZrO}_{2}$ and surfacemodified nano- $\mathrm{ZrO}_{2}\left(\mathrm{ZrO}_{2}\right.$.trioxadecanoic acid $\left(\mathrm{ZrO}_{2}\right.$. TODA) and $\mathrm{ZrO}_{2}$.polyacrylate) evaluated in the present study provide a first insight on their pulmonary effects.

Nanoparticular $\mathrm{CeO}_{2}$ is widely used e.g. in solar cells, as additive in diesel and automotive catalytic converters, as UV absorbent, for glass or ceramic applications and as polishing agent for silicon-wafers. The oxidative and lung toxicity potential of nano- $\mathrm{CeO}_{2}$ has recently been demonstrated in a first acute inhalation study [15] in which $641 \mathrm{mg} / \mathrm{m}^{3}$ were applied to rats for $4 \mathrm{~h}$ in accordance with OECD test guideline (TG) 403. Under these experimental conditions, acute signs of inflammation and oxidative damage including reduced tissue glutathione and increased levels of malondialdehyde were observed. All of these effects were partially reversible within 14 days, whereas the $\mathrm{CeO}_{2}$ particles persisted inside the alveoli and lung tissue for a longer period. The results from this first inhalation study were consistent with previous instillation studies [16,17] and with earlier reports on the occurrence of pneumoconiosis in workers exposed to (micron-scale) $\mathrm{CeO}_{2}$ particles $[18,19]$. Two types of $\mathrm{CeO}_{2}$ nanomaterials were tested in the present study, which partly differed in chemical composition, with the one being pure and the other being doped with a low percentage of aluminium.

As a rule, the tested aerosol concentration ranges encompass the nuisance dust limit laid down by the German Federal Ministry of Labour and Social Affairs, i.e. $1.25 \mathrm{mg} / \mathrm{m}^{3}$ for granular respirable dusts that can reach the alveoli $[20,21]$. The highest concentrations were selected to challenge the lung clearance mechanism under conditions of beginning lung overload, which was usually at $10 \mathrm{mg} / \mathrm{m}^{3}$. For coated nano- $\mathrm{TiO}_{2}\left(\mathrm{~T}\right.$-Lite $\left.\mathrm{SF}^{\mathrm{m}}\right)$, this concentration had caused adverse effects in previously performed subchronic studies. Lower or higher concentrations were selected, as appropriate, based on existing data from previous toxicological tests, e.g. $50 \mathrm{mg} / \mathrm{m}^{3}$ for $\mathrm{BaSO}_{4}$. Aerosols were characterized with respect to size distribution and number concentration using ISOstandardized methods or, alternatively, characterization methods recommended by the OECD.

The biological effects of the nanomaterials in rats were determined by analysing the bronchoalveolar lavage fluid (BALF) and blood samples as well as by performing histopathological examinations of all respiratory tract tissues. For all test substances, the organ burden, i.e. the content of test material, was determined in the lung and lung-associated mediastinal lymph nodes, and for most test substances, also in extra-pulmonary organs. Additional information, i.e. cell proliferation rates, an early indicator for epithelial hypertrophy, and apoptotic reactions in the terminal bronchi and alveoli, cytokine profiles in the blood, BALF and/or lung tissue homogenates, or transmission electron microscopic (TEM) evaluation of organs, were additionally collected for selected substances.

In assessing whether effects were to be considered treatment-related or incidental, they were not only compared to the corresponding effects occurring in the control groups, but also to historical control data (c.f. Supplementary Information (SI), Additional file 1: Table S1, for historical control ranges of BALF and lung tissue homogenate parameters of male $\mathrm{Crl}: \mathrm{Wi}(\mathrm{Han})$ rats, 8-12 weeks of age).

\section{Results}

\section{Characterization of the test materials}

A comprehensive overview of the physico-chemical characteristics of the test materials is provided in Table 1. Details of this characterization have previously been published for those test materials that were delivered as powders (i.e. $\mathrm{TiO}_{2}$, both $\mathrm{ZnO}$, both $\mathrm{CeO}_{2}, \mathrm{BaSO}_{4}$, nano$\left.\mathrm{ZrO}_{2}\right)$ [22] and for those materials that were delivered as suspensions (i.e. all $\mathrm{SiO}_{2} ; \mathrm{ZrO}_{2}$.TODA; $\mathrm{ZrO}_{2}$.acrylate) [23]. Morphological images of all test substances, except for $\mathrm{SiO}_{2}$.acrylate, obtained by scanning electron microscopy (SEM) and TEM, are presented in Figures 1 and 2.

\section{Characterization of the test aerosols}

The achieved aerosol concentrations were generally close to the corresponding target concentrations (Table 2). Evaluation of the particle size distribution confirmed that the aerosols were respirable for rats. Size measurements in the submicrometer range conducted with the Scanning Mobility Particle Sizer (SMPS) revealed that the aerosols consisted of few primary particles in the range of 14 to $90 \mathrm{~nm}$ and of agglomerates with diameters up to 3 micrometres, with the majority of the agglomerates (typically 80\%) being in the submicrometre range.

\section{Toxicological effects}

An overview of the toxicological effects elicited by the 13 nanomaterials and micron-scale $\mathrm{ZnO}$ is provided in Table 3, with details on affected BALF parameters presented in Figures 3A-3F and the Supplementary Information (SI) Additional file 1: Tables S1-S9. The incidences and severities of the histological findings induced by the $\mathrm{TiO}_{2}, \mathrm{ZnO}$, and $\mathrm{CeO}_{2}$ test materials are summarized in SI, Additional file 2: Tables S10-S15. The following sub-sections present the toxicological effects observed for each test material, and the subsequent 
Table 1 Physico-chemical characterization of the 14 test materials (i.e. 13 nanomaterials and micron-scale $\mathrm{ZnO}$ )

\begin{tabular}{|c|c|c|c|c|c|c|c|c|c|c|c|c|c|c|}
\hline & $\begin{array}{l}\text { Al-doped } \\
\mathrm{CeO}_{2}\end{array}$ & $\mathrm{CeO}_{2}$ & $\begin{array}{l}\text { Uncoated } \\
\mathrm{ZrO}_{2}\end{array}$ & 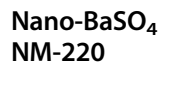 & $\begin{array}{l}\mathrm{TiO}_{2} \\
\left(\mathrm{~T}-\text { Lite } \mathrm{SF}^{\mathrm{TM}}\right)\end{array}$ & $\begin{array}{l}\text { coated } \\
\text { nano-Zno } \\
\text { NM-111 }\end{array}$ & $\begin{array}{l}\text { micron- } \\
\text { scale } \\
\text { ZnO }\end{array}$ & $\begin{array}{l}\mathrm{SiO}_{2} \\
\text { naked }\end{array}$ & $\begin{array}{l}\mathrm{SiO}_{2} \text {. } \\
\text { acrylate }\end{array}$ & $\mathrm{SiO}_{2}$. PEG & $\begin{array}{l}\mathrm{SiO}_{2} \\
\text { amino }\end{array}$ & $\begin{array}{l}\mathrm{SiO}_{2} . \\
\text { phosphate }\end{array}$ & $\begin{array}{l}\mathrm{ZrO}_{2} \\
\text { acrylate }\end{array}$ & $\begin{array}{l}\mathrm{ZrO}_{2} \\
\mathrm{TODA}\end{array}$ \\
\hline $\begin{array}{l}\text { PPS/shape } \\
\text { (TEM; nm) }\end{array}$ & $\begin{array}{l}2-160 \\
\text { globular }\end{array}$ & $\begin{array}{l}0-200 \\
\text { globular }\end{array}$ & $\begin{array}{l}25-60 \\
\text { globular }\end{array}$ & 25 globular & $\begin{array}{l}15 \times 50 \\
\text { Aspect ratio } \\
>3 \text {, fiber }\end{array}$ & $\begin{array}{l}\text { 20-200 } \\
\text { mostly } \\
\text { globular }\end{array}$ & $\begin{array}{l}50-500 \\
\text { globular }\end{array}$ & 15 & 20 & 15 & 15 & 15 & 9 & 9 \\
\hline $\begin{array}{l}\text { Agglomerate } \\
\text { size/shape } \\
\text { (SEM; nm) }\end{array}$ & $>20,000$ & $>10,000$ & $\begin{array}{l}1,000- \\
5,000\end{array}$ & $\begin{array}{l}2,800- \\
15,000 \\
\text { spheres }\end{array}$ & & $>20,000$ & 2,500 & & & & & & & \\
\hline $\begin{array}{l}\text { Crystallite size } \\
\text { (XRD; nm) }\end{array}$ & 23 & 36 & 45 & 36 & 24 & 61 & $>100$ & n.a. & n.a. & n.a. & n.a. & n.a. & п.а. & n.a. \\
\hline $\begin{array}{l}\text { Crystalline phase } \\
\text { (XRD) }\end{array}$ & $\begin{array}{l}\text { Cerianite } \\
\text { cubic }\end{array}$ & $\begin{array}{l}\text { Cerianite } \\
\text { cubic }\end{array}$ & $\begin{array}{l}\mathrm{ZrO2} \\
\text { tetragonal }\end{array}$ & $\begin{array}{l}\text { Barite } \\
\text { orthorhombic }\end{array}$ & $\begin{array}{l}\text { Rutile, } \\
\text { (minimally } \\
\text { anatase) }\end{array}$ & $\begin{array}{l}\text { Zincite, } \mathrm{ZnO} \\
\text { hexagonal }\end{array}$ & $\begin{array}{l}\text { Zincite, } \\
\text { ZnO } \\
\text { hexagonal }\end{array}$ & n.a. & n.a. & n.a. & n.a. & n.a. & n.a. & n.a. \\
\hline $\begin{array}{l}\text { Pore sizes } \\
\text { (Hg porosimetry; nm) }\end{array}$ & $\begin{array}{l}30 ; 800 ; \\
40,000\end{array}$ & $\begin{array}{l}30 ; \\
20,000\end{array}$ & $\begin{array}{l}40 ; 1,000 \\
15,000\end{array}$ & $30 ; 5,000$ & $20 ; 30,000$ & $30 ; 40,000$ & $\begin{array}{l}5 ; 200 \\
7,000\end{array}$ & n.a. & n.a. & n.a. & n.a. & n.a. & n.a. & n.a. \\
\hline $\begin{array}{l}\text { Specific surface area } \\
\text { (BET nitrogen } \\
\text { adsorption } \\
\text { and Hg intrusion } \\
\text { porosimetry; } \mathrm{m}^{2} / \mathrm{g} \text { ) }\end{array}$ & $46.0(62)$ & 33.0 (34) & $24.9(29)$ & $41.4(33)$ & $100.0(82)$ & $12.0(20)$ & $5.6(55)$ & n.a. & n.a. & n.a. & n.a. & n.a. & n.a. & n.a. \\
\hline $\begin{array}{l}\text { Surface chemistry } \\
\text { (XPS; supported by } \\
\text { SIMS; as necessary; } \\
\text { Atom\%/qualitative) }\end{array}$ & $\begin{array}{l}\text { Ce: } 21 ; \mathrm{Al} \\
\text { 9; O: 56; } \\
\text { C: } 9 ; \mathrm{Zr}: 4 ; \\
\mathrm{N}: 1\end{array}$ & $\begin{array}{l}\text { Ce: 16; O: } \\
61 ; \text { C: } 9 \\
(C-C, O-C \\
=O) ; A l \\
9 ; \mathrm{Zr}: 5\end{array}$ & $\begin{array}{l}\text { Zr: 24; O: } \\
\text { 53; C: } 19 \\
(\mathrm{C}-\mathrm{C}, \mathrm{C}-\mathrm{O}, \\
\mathrm{O}-\mathrm{C}=\mathrm{O}) \\
\mathrm{N}: 3 ; \mathrm{Al}: 1\end{array}$ & $\begin{array}{l}\text { Ba: 13; O; 52; } \\
\text { C: 17; S: 11; } \\
\text { Cl: } 3 ; \mathrm{P}: 3 ; \mathrm{N}: \\
1\end{array}$ & $\begin{array}{l}\text { Ti: 16; O: 63; } \\
\text { C: 9; Al: 7; Si: } \\
\text { 5; Na: <1; } \\
\text { dimethicone/ } \\
\text { methicone } \\
\text { copolymer as } \\
\text { surface } \\
\text { coating }\end{array}$ & $\begin{array}{l}\text { Zn: 1; C: 64; } \\
\text { (C-C, C-O, } \\
\text { peptide) O: } \\
\text { 19; N: 12; Na: } \\
\text { 2; P: 2; Cl: 1; } \\
\text { 3.5\% } \\
\text { triethoxy- } \\
\text { octylsilane }\end{array}$ & $n / d$ & $\begin{array}{l}\text { Si: 29; O: } \\
\text { 66; C: } 4 \\
\text { (C-C, C-H, } \\
\text { C-O, C= } \\
\text { O) Na: } 1\end{array}$ & $\begin{array}{l}\text { Si: 21; O: } \\
\text { 54C: } 24 \\
\text { (C-C, some } \\
\text { C-O, C=O); } \\
\text { Na: 1; SIMS: } \\
\text { poly- } \\
\text { methacrylic } \\
\text { acid/3- } \\
\text { methac- } \\
\text { ryloxypropyl }\end{array}$ & $\begin{array}{l}\text { SIMS: } \\
\text { expected } \\
\text { fragments } \\
\text { of PEG500 } \\
\left(\mathrm{CH}_{2} \mathrm{CH}_{2} \mathrm{O}\right)\end{array}$ & $\begin{array}{l}\text { SIMS: } \\
\text { expected } \\
\text { fragments } \\
\text { of } \\
\text { aminosilane }\end{array}$ & $\begin{array}{l}\text { Si: } 29 ; \mathrm{O}: 66 ; \\
\mathrm{C}: 4.6 ; \mathrm{Na} \text {; } \\
0.5 ; \\
\text { expected P, } \\
\mathrm{N} \text { not } \\
\text { detec-ted } \\
\text { by XPS, but } \\
\mathrm{PO}_{2}, \mathrm{PO}_{3} \\
\text { fragments } \\
\text { by SIMS }\end{array}$ & $\begin{array}{l}\text { Zr 23; O: } \\
\text { 58; C: 19; } \\
\text { SIMS: } \\
\text { expected } \\
\text { acrylic } \\
\text { acid }\end{array}$ & $\begin{array}{l}\text { Zr; 24; O: } \\
\text { 63; C: 11; } \\
\text { N: 0.7; S: } \\
\text { 0.2; SIMS: } \\
\text { expected } \\
\text { trioxa- } \\
\text { decanoic } \\
\text { acid }\end{array}$ \\
\hline $\begin{array}{l}\text { Photocatalysis: } \\
\text { photon efficiency, } \\
\text { unitless } s^{a}\end{array}$ & $8.8 \mathrm{E}-04$ & $1.6 \mathrm{E}-03$ & 7.0E-04 & $1.1 \mathrm{E}-03$ & $5.3 \mathrm{E}-04$ & $\begin{array}{l}\text { n.m. } \\
\text { (hydrophobic) }\end{array}$ & $5.0 \mathrm{E}-01$ & 1.7E-5 & $5.9 \mathrm{E}-5$ & $6.2 \mathrm{E}-5$ & $8.8 \mathrm{E}-5$ & $1.9 \mathrm{E}-4$ & $2.9 \mathrm{E}-5$ & $5.8 \mathrm{E}-5$ \\
\hline $\begin{array}{l}\text { Surface charge } \\
\text { Iso-electric point/ } \\
\text { Mobility at pH } 7\end{array}$ & $\begin{array}{l}8.5 / 1.4 \\
(\mu \mathrm{m} / \mathrm{s}) / \mathrm{N} / \\
\mathrm{cm})\end{array}$ & $\begin{array}{l}7.5 / 0.5 \\
(\mu \mathrm{m} / \mathrm{s}) \mathrm{N} / \\
\mathrm{cm})\end{array}$ & $\begin{array}{l}6.5 /-0.9 \\
(\mu \mathrm{m} / \mathrm{s}) / \mathrm{N} / \\
\mathrm{cm})\end{array}$ & $\begin{array}{l}3.3 /-2.2(\mu \mathrm{m} / \\
\text { s) } N / \mathrm{cm})\end{array}$ & $\begin{array}{l}6.5 /-0.2(\mu \mathrm{m} / \\
\mathrm{s}) / \mathrm{N} / \mathrm{cm})\end{array}$ & $\begin{array}{l}\text { n.m. } \\
\text { (agglo- } \\
\text { merated) }\end{array}$ & $\begin{array}{l}\text { n.m. } \\
\text { (agglo- } \\
\text { merated) }\end{array}$ & $<1 /-$ & $<1 /-$ & 4/- & 7.2/- & $<1 /-$ & $<1 /-$ & 7.1/- \\
\hline $\begin{array}{l}\text { Zeta-potential at } \\
\text { pH } 7(\mathrm{mV})\end{array}$ & 18 & 6 & -12 & -28 & -3 & & & -38 & -47 & -26 & 0 & -43 & -39 & -6 \\
\hline $\begin{array}{l}\text { Surface reactivity } \\
(E S R+C P H)^{b}\end{array}$ & & & & & & & & $\begin{array}{c}4 \\
(p-f \text { s: } 0.8)\end{array}$ & n.d. & $\begin{array}{c}1 \\
(p-f s: 3.4)\end{array}$ & $\begin{array}{l}1(p-f s: \\
1.1)\end{array}$ & $\begin{array}{c}2.2 \\
(p-f s: 1.2)\end{array}$ & $\begin{array}{c}1 \\
(p-f s: 2)\end{array}$ & $\begin{array}{c}0.54 \\
(p-f s: 5.7)\end{array}$ \\
\hline $\begin{array}{l}\text { Formation of } \mathrm{OH} \\
\text { radicals (ROS) }\end{array}$ & & & & & & & & $\begin{array}{c}11 \\
(p-f s: 6.3)\end{array}$ & n.d. & $\begin{array}{c}11 \\
(p-f s: 13)\end{array}$ & $\begin{array}{c}21 \\
(p-f s: 5.2)\end{array}$ & 19 (p-f s: 5) & $\begin{array}{c}3.6 \\
(p-f s: 1.5)\end{array}$ & $\begin{array}{c}0.94 \\
(p-f s: 1.3)\end{array}$ \\
\hline
\end{tabular}


Table 1 Physico-chemical characterization of the 14 test materials (i.e. 13 nanomaterials and micron-scale $\mathrm{ZnO}$ ) (Continued)

\begin{tabular}{|c|c|c|c|c|c|c|c|c|c|c|c|c|c|c|}
\hline $\begin{array}{l}\text { Particle size/ } \\
\text { dispersability in } \\
\text { water }\end{array}$ & $603 / 20$ & $90 / 3.0$ & $\begin{array}{l}1,500 / 38 \\
<0.1 \mathrm{wt} \% \\
<100 \mathrm{~nm}\end{array}$ & $116 / 4.6$ & $33 / 1.7$ & $\begin{array}{l}\text { Agglom:; } \\
<0.01 \mathrm{wt} \% \\
<100 \mathrm{~nm}\end{array}$ & $\begin{array}{l}5,100 / 20 ; \\
<0.1 \mathrm{wt} \% \\
<100 \mathrm{~nm}\end{array}$ & $19 / 1$ & $23 / 1$ & $21 / 1$ & $20 / 1$ & $20 / 1$ & $27 / 3$ & $11 / 1$ \\
\hline $\begin{array}{l}\text { in DMEM/FCS } \\
\text { (AUC; } D_{50}(\mathrm{~nm}) / \\
\text { AAN (qualitative)) }\end{array}$ & $94 / 3.1$ & $54 / 1.8$ & $87 / 2.2$ & $285 / 11$ & $\begin{array}{l}3,900 / 195 ; \\
2 \mathrm{wt} \% \\
<100 \mathrm{~nm}\end{array}$ & $550 / 18$ & $950 / 3.8$ & $420 / 28$ & $26 / 1$ & $3200 / 213$ & $1350 / 90$ & $30 / 2$ & $315 / 32$ & $860 / 86$ \\
\hline $\begin{array}{l}\text { Solubility in water } \\
\text { and in DMEM/FCS }\end{array}$ & $\begin{array}{l}\mathrm{Ce}, \mathrm{Al} \\
<0.1 \mathrm{ppm}\end{array}$ & $\begin{array}{l}\mathrm{Ce} \\
<0.1 \mathrm{ppm}\end{array}$ & $\begin{array}{l}\mathrm{Zr} \\
<0.1 \mathrm{ppm}\end{array}$ & Ba 6 ppm & $\begin{array}{l}\text { Ti } 5 \text { ppm } \\
\text { Ti } 5 \text { ppm }\end{array}$ & $\begin{array}{l}\text { Soluble } \\
\text { at } \mathrm{pH}<6\end{array}$ & $\begin{array}{l}\mathrm{Zn} \\
<5 \mathrm{ppm} \\
\mathrm{Zn} \\
50 \mathrm{ppm}\end{array}$ & & & & & & & \\
\hline
\end{tabular}

${ }^{a}$ Catalytic events per photon impinging on the surface, as specified in DIN 52980

${ }^{b}$ Surface reactivity and ROS formation were determined relative to the 'reference material' deuterium oxide $\left(\mathrm{D}_{2} \mathrm{O} ;{ }^{2} \mathrm{H}_{2} \mathrm{O}\right)$. Assuming a $30 \%$ variability of the methodology, only measurements $>1.3$ are considered relevant. Of note, this value should only serve as a guiding principle, and not as an absolute value.

Abbreviations: $A A N$ average agglomeration number; derived from the ratio of the volume-based median particle size to the average equivalent spherical volume derived from the BET gas adsorption, $A U C$ analytical ultracentrifugation, $B E T$ method of Brunauer-Emmett-Teller, D medium value of the particle size distribution. DMEM/FCS Dulbecco's Modified Eagle Medium supplemented with $10 \%$ fetal calf serum, ESR + CPH Electron spin reson spin tron spectroscopy, $X R D$ x-ray diffusion. 


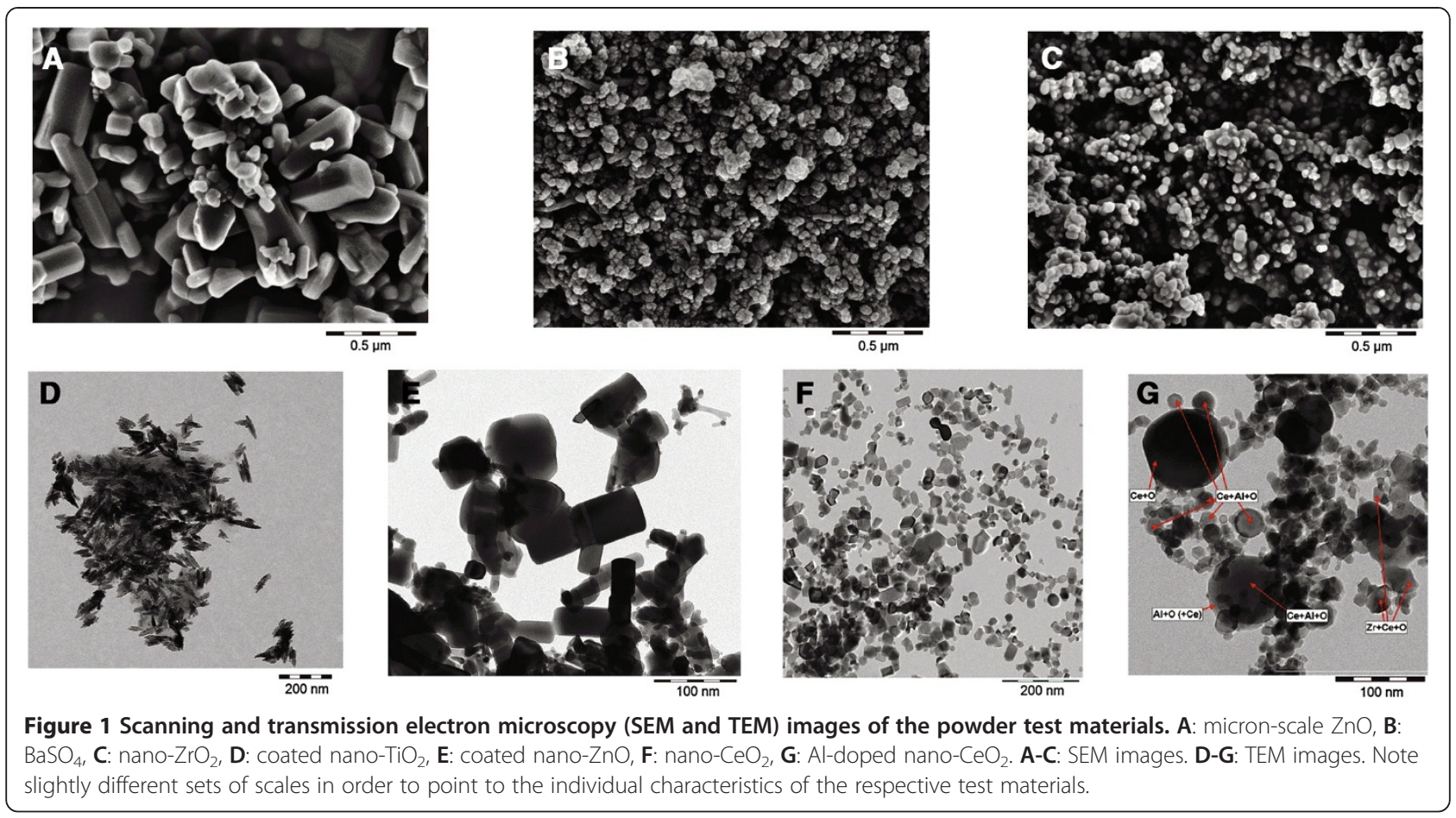

Organ burden analysis summarizes the outcome of the organ burden analysis (Table 4). An overview of the study design, indicating which specific examinations were conducted in the animal groups treated with either of the test materials, is provided in Table 5.

\section{Coated nano- $\mathrm{TiO}_{2}\left(\mathrm{~T}\right.$-Lite $\left.\mathrm{SF}^{\mathrm{TM}}\right)$}

Inhalation exposure to $10 \mathrm{mg} / \mathrm{m}^{3}$ coated nano- $\mathrm{TiO}_{2}$ caused markedly increased polymorphonuclear (PMN) neutrophil and monocyte counts in the BALF differential cell counts, accompanied by increased total cell

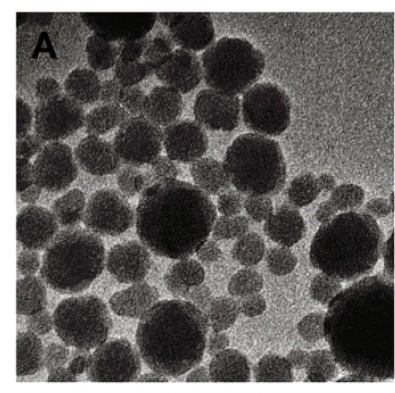

$-\overline{100 \mathrm{~nm}}$

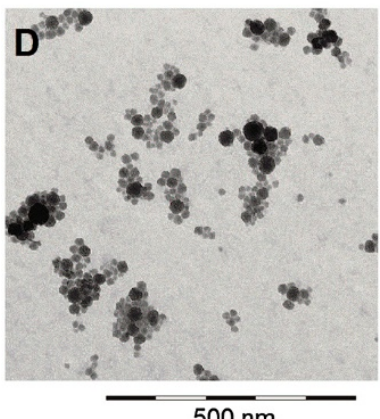

$500 \mathrm{~nm}$
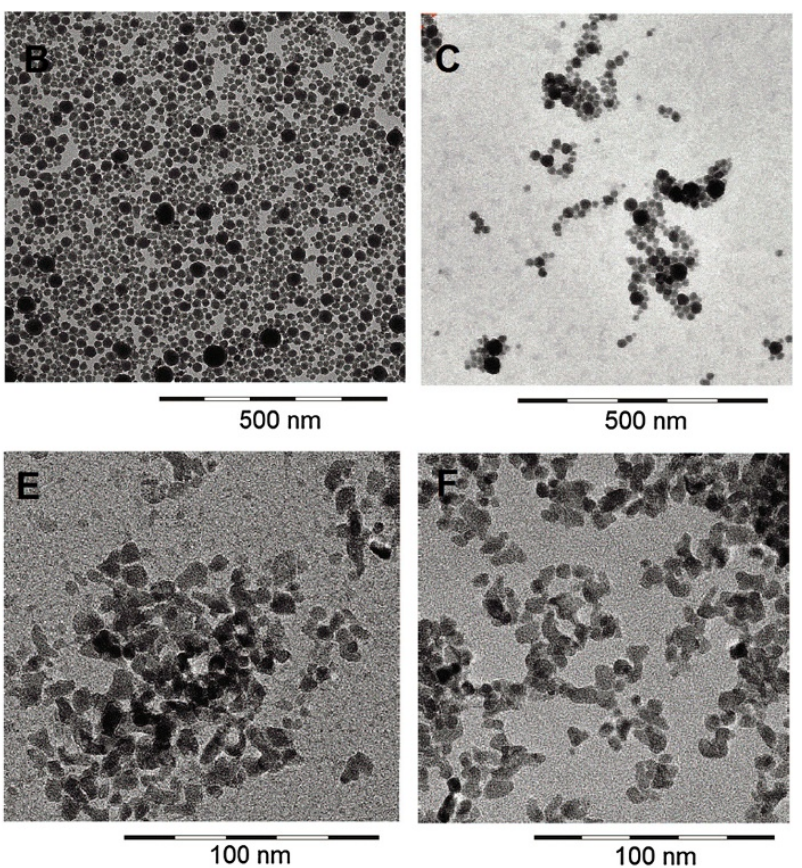

Figure 2 Scanning electron microscopy images of the suspension test materials. A: $\mathrm{SiO}_{2} \cdot \mathrm{naked}, \mathbf{B}: \mathrm{SiO}_{2} \cdot \mathrm{PEG}_{1} \mathbf{C}: \mathrm{SiO}_{2} \cdot \mathrm{amino}_{1} \mathbf{\mathbf { D }}: \mathrm{SiO}$. phosphate, $\mathbf{E}: \mathrm{ZrO}_{2}$.TODA, $\mathbf{F}: \mathrm{ZrO}_{2}$.acrylate. Note slightly different sets of scales in order to point to the individual characteristics of the respective test materials. 
Table 2 Targeted and measured test substance concentrations and particle size distributions

\begin{tabular}{|c|c|c|c|c|c|c|}
\hline \multirow[b]{2}{*}{ Test substance } & \multirow{2}{*}{$\begin{array}{c}\text { Targeted } \\
\text { concentrations } \\
\left(\mathrm{mg} / \mathrm{m}^{3}\right)\end{array}$} & \multirow{2}{*}{$\begin{array}{c}\text { Measured } \\
\text { concentrations, } \\
\text { mean } \pm \text { SD } \\
\left(\mathrm{mg} / \mathrm{m}^{3}\right)\end{array}$} & \multicolumn{2}{|c|}{ MMAD $(\mu \mathrm{m}) / G S D$} & \multirow{2}{*}{$\begin{array}{c}\text { Particle count } \\
\text { concentration } \\
\text { measured by } \\
\text { SMPS } \\
\left(\text { particle } / \mathrm{cm}^{3} \text { ) }\right.\end{array}$} & \multirow{2}{*}{$\begin{array}{c}\text { Particle } \\
\text { count } \\
\text { Median } \\
(\mu \mathrm{m})\end{array}$} \\
\hline & & & Measurement 1 & Measurement 2 & & \\
\hline & 0.5 & $0.6 \pm 0.1$ & $0.8 / 3.4$ & $0.7 / 4.4$ & 33905 & 0.131 \\
\hline \multirow[t]{2}{*}{ Coated nano- $\mathrm{TiO}_{2}$} & 2 & $2.0 \pm 0.1$ & $0.4 / 3.1$ & $0.2 / 4.0$ & 114889 & 0.153 \\
\hline & 10 & $10.7 \pm 1.2$ & $0.4 / 3.0$ & $0.4 / 3.6$ & 205660 & 0.167 \\
\hline \multirow[t]{2}{*}{ Micron-scale ZnO } & 12.5 & $15.3 \pm 1.6$ & $1.0 / 2.2$ & $1.1 / 2.3$ & 219031 & 0.167 \\
\hline & 0.5 & $0.6 \pm 0.2$ & $0.9 / 2.4$ & $1.3 / 2.4$ & 22126 & 0.144 \\
\hline \multirow[t]{3}{*}{ Coated nano-ZnO (NM-111) } & 2.5 & $2.8 \pm 0.6$ & $0.8 / 2.5$ & $0.8 / 2.8$ & 87044 & 0.177 \\
\hline & 12.5 & $13.8 \pm 2.0$ & $0.8 / 2.4$ & $0.9 / 2.4$ & 159381 & 0.198 \\
\hline & 0.5 & $0.5 \pm 0.1$ & $1.3 / 3.0$ & $1.7 / 3.4$ & 20167 & 0.106 \\
\hline \multirow{4}{*}{$\mathrm{SiO}_{2}$.naked } & 2.5 & $2.4 \pm 0.1$ & $1.0 / 2.3$ & $1.2 / 2.2$ & 47866 & 0.101 \\
\hline & 10 & $10.4 \pm 1.3$ & $1.3 / 2.2$ & $1.5 / 2.3$ & 130972 & 0.127 \\
\hline & 50 & $52.6 \pm 4.3$ & $2.0 / 2.8$ & $2.2 / 2.6$ & 172204 & 0.114 \\
\hline & 0.5 & $0.6 \pm 0.1$ & $1.1 / 2.4$ & $1.2 / 2.3$ & 13607 & 0.090 \\
\hline \multirow[t]{3}{*}{$\mathrm{SiO}_{2} \cdot$ acrylate } & 2.0 & $2.1 \pm 0.2$ & $1.0 / 2.3$ & $1.0 / 2.3$ & 30623 & 0.100 \\
\hline & 10 & $9.7 \pm 0.4$ & $1.1 / 2.8$ & $1.1 / 2.3$ & 159381 & 0.110 \\
\hline & 2 & $2.05 \pm 0.12$ & $1.0 / 2.8$ & $1.0 / 2.5$ & 17080 & 0.093 \\
\hline \multirow[t]{3}{*}{$\mathrm{SiO}_{2} \cdot \mathrm{PEG}$} & 10 & $10.0 \pm 1.4$ & $1.0 / 2.7$ & $1.1 / 2.7$ & 73384 & 0.100 \\
\hline & 50 & $54.1 \pm 1.0$ & $1.3 / 2.8$ & $1.3 / 2.8$ & 164639 & 0.125 \\
\hline & 2 & $2.9 \pm 0.6$ & $0.8 / 3.6$ & $0.9 / 2.6$ & 109566 & 0.09 \\
\hline \multirow[t]{3}{*}{$\mathrm{SiO}_{2}$.phosphate } & 10 & $10.0 \pm 1.2$ & $1.4 / 2.6$ & $1.3 / 2.3$ & 105863 & 0.09 \\
\hline & 50 & $51.5 \pm 5.4$ & $1.4 / 2.5$ & $1.6 / 2.4$ & 308408 & 0.10 \\
\hline & 2 & $2.1 \pm 0.4$ & $0.8 / 2.4$ & $0.9 / 4.0$ & 11036 & 0.09 \\
\hline \multirow[t]{3}{*}{$\mathrm{SiO}_{2}$.amino } & 10 & $10.2 \pm 1.4$ & $1.8 / 2.0$ & $1.4 / 2.2$ & 146680 & 0.10 \\
\hline & 50 & $50.4 \pm 3.7$ & $1.7 / 2.7$ & $1.3 / 2.8$ & 282401 & 0.10 \\
\hline & 2 & $2.5 \pm 0.3$ & $1.3 / 2.4$ & $1.2 / 2.2$ & 71945 & 0.173 \\
\hline \multirow[t]{3}{*}{$\mathrm{Nano}^{-\mathrm{BaSO}_{4}(\mathrm{NM}-220)}$} & 10 & $13.1 \pm 0.7$ & $1.5 / 2.1$ & $1.4 / 2.3$ & 245438 & 0.198 \\
\hline & 50 & $53.4 \pm 9.7$ & $1.1 / 2.2$ & $0.9 / 2.3$ & 258642 & 0.188 \\
\hline & 0.5 & $0.5 \pm 0.1$ & $1.6 / 2.1$ & $1.3 / 2.0$ & 8580 & 0.091 \\
\hline \multirow[t]{3}{*}{$\mathrm{Nano}_{-} \mathrm{ZrO}_{2}$} & 2.5 & $2.6 \pm 0.3$ & $1.3 / 2.0$ & $1.4 / 2.3$ & 16024 & 0.138 \\
\hline & 10 & $9.6 \pm 1.2$ & $1.8 / 2.2$ & $2.0 / 1.8$ & 76924 & 0.149 \\
\hline & 2 & $2.0 \pm 0.1$ & $1.3 / 4.0$ & $1.2 / 3.9$ & 59496 & 0.08 \\
\hline \multirow[t]{3}{*}{$\mathrm{ZrO}_{2} \cdot \mathrm{TODA}$} & 10 & $10.6 \pm 0.3$ & $1.0 / 4.7$ & $1.1 / 4.2$ & 72398 & 0.11 \\
\hline & 50 & $52.2 \pm 1.1$ & $1.5 / 3.3$ & $1.2 / 4.3$ & 124267 & 0.13 \\
\hline & 2 & $1.9 \pm 0.1$ & $0.6 / 2.9$ & $0.7 / 2.7$ & 54218 & 0.06 \\
\hline \multirow[t]{3}{*}{$\mathrm{ZrO}_{2}$.acrylate } & 10 & $10.1 \pm 1.0$ & $1.0 / 2.6$ & $0.8 / 2.8$ & 133269 & 0.06 \\
\hline & 50 & $50.5 \pm 4.7$ & $1.4 / 2.7$ & $1.3 / 3.4$ & 166557 & 0.06 \\
\hline & 0.5 & $0.8 \pm 0.3$ & $0.6 / 2.4$ & $0.7 / 2.9$ & 47745 & 0.111 \\
\hline \multirow[t]{3}{*}{ Nano- $\mathrm{CeO}_{2}$} & 2.5 & $3.0 \pm 0.2$ & $0.9 / 2.3$ & $0.8 / 2.3$ & 126354 & 0.144 \\
\hline & 10 & $11.6 \pm 0.5$ & $0.8 / 2.5$ & $0.7 / 2.4$ & 458415 & 0.172 \\
\hline & 0.5 & $0.6 \pm 0.3$ & $1.3 / 2.1$ & $1.1 / 2.3$ & 39695 & 0.252 \\
\hline \multirow[t]{2}{*}{ Al-doped nano- $\mathrm{CeO}_{2}$} & 2 & $2.1 \pm 0.5$ & $2.2 / 1.9$ & $1.8 / 1.9$ & - & - \\
\hline & 10 & $9.2 \pm 2.6$ & $2.4 / 2.1$ & $1.8 / 1.9$ & 82383 & 0.200 \\
\hline
\end{tabular}


Table 3 Summary of the test results obtained for 13 nanomaterials and micron-scale ZnO in rat short-term inhalation studies

\begin{tabular}{|c|c|c|c|c|c|}
\hline Test material & $\begin{array}{l}\text { Target } \\
\text { con-centrations } \\
{\left[\mathrm{mg} / \mathrm{m}^{3}\right]}\end{array}$ & $\begin{array}{l}\text { NOAEC } \\
\left(\mathrm{mg} / \mathrm{m}^{3}\right)\end{array}$ & Findings in the BALF & $\begin{array}{l}\text { Pathological and histological } \\
\text { findings }\end{array}$ & $\begin{array}{l}\text { Reversibility of } \\
\text { effects }\end{array}$ \\
\hline $\begin{array}{l}\text { Coated nano- } \mathrm{TiO}_{2} \\
\left.\text { (T-Lite } \mathrm{SF}^{\mathrm{TM}}\right)\end{array}$ & $0.5,2.0,10.0$ & 0.5 & $\begin{array}{l}\text { Increased total cell counts, and } \\
\text { PMN neutrophils, monocytes, } \\
\text { total protein, GGT, LDH, ALP and } \\
\text { NAG (cytokines not measured) }\end{array}$ & $\begin{array}{l}\text { Lung: pigment-loaded alveolar } \\
\text { macrophages and slight diffuse } \\
\text { histiocytosis }\end{array}$ & $\begin{array}{l}\text { Slight increases in } \\
\text { BALF parameters } \\
\text { remaining }\end{array}$ \\
\hline
\end{tabular}

Micron-scale ZnO 12.5

n.a.

Coated nano-

$0.5,2.5,12.5$

0.5

$\mathrm{ZnO}(\mathrm{NM}-111)$

$\begin{array}{ll}\mathrm{SiO}_{2} . \text { naked } & 0.5 ; 2.5 ; 10.0 ; \quad 2.5 \\ & 50.0\end{array}$

local effects: $\geq 10 ; \quad$ No adverse findings systemic effects: 0.5
Increased total cell counts and PMN neutrophils, lymphocytes, monocytes, total protein, GGT, LDH, ALP and NAG. Many mediators increased; above 10fold as compared to respective control values: clusterin; CRP. MCP-1; MCP-3; MDC; MPO; OPN. (Monocyte data not shown in Additional file 1: Table S1)

Increased total cell counts and PMN neutrophils, lymphocyte, monocyte, total protein, GGT, LDH, ALP and NAG. Many mediators increased; above 10fold at highest concentration as compared to respective control values: CINC-1; clusterin; cystatin C; GCP-2; MCP-1; M-CSF; MDC; $\mathrm{MPO} ; \mathrm{OPN}$

Slightly increased PMN neutrophils and lymphocytes

\begin{tabular}{|c|c|c|}
\hline $\mathrm{SiO}_{2} \cdot \mathrm{PEG}$ & $2.0 ; 10.0 ; 50.0$ & $\geq 50$ \\
\hline $\mathrm{SiO}_{2}$.phosphate & $2.0 ; 10.0 ; 50.0$ & $\geq 50$ \\
\hline $\mathrm{SiO}_{2}$.amino & $2.0 ; 10.0 ; 50.0$ & $\geq 50$ \\
\hline $\begin{array}{l}\text { Nano-BaSO } \\
\text { (NM-220) }\end{array}$ & $2.0 ; 10.0 ; 50.0$ & $\geq 50$ \\
\hline Nano- $\mathrm{ZrO}_{2}$ & $0.5,2.5,10.0$ & $\geq 10$ \\
\hline $\mathrm{ZrO}_{2} \cdot \mathrm{TODA}$ & $2.0 ; 10.0 ; 50.0$ & $\geq 50$ \\
\hline $\mathrm{rO}_{2}$.acrylate & $2.0 ; 10.0 ; 50.0$ & $>50$ \\
\hline Nano- $\mathrm{CeO}_{2}$ & $0.5,2.5,10.0$ & 0.5 \\
\hline
\end{tabular}

Al-doped
nano- $\mathrm{CeO}_{2}$$\quad$ 0.5, $2.010 .0 \quad<0.5$

No adverse findings

No adverse findings

No adverse findings

No adverse findings

No adverse findings

No adverse findings

No adverse findings

Changes of all cytological and biochemical parameters in BALF; increased levels of Changes of CINC-1, IFNY, IL-1a, MCP-1, MCSF, in BALF and lung tissue

Changes of all cytological and biochemical parameters in BALF, increased MCP-1 and CINC-1 in BALF, increased IL1- $a$ in lung tissue
Nasal cavity: severe multifocal necrosis of olfactory epithelia Lung: Increased absolute (+27\%) and relative lung $(+34 \%)$ weight, bronchoalveolar hyperplasia, histiocytosis, granulocytic infiltration Mediastinal lymph nodes: Iympho-reticulo-cellular hyperplasia

Nasal cavity: moderate multifocal necrosis of olfactory epithelia Lung: histiocytosis, granulocytic infiltration Mediastinal lymph nodes: lympho-reticulo-cellular hyperplasia

Slightly increased neutrophil counts in blood after the end of exposure (data not shown) Respiratory tract: Multifocal macrophage aggregates; Exacerbation towards a slight multifocal inflammation after 3 weeks (data not shown)

Respiratory tract: no adverse effects, Spleen: increased weight (+ 25\%) without histological correlate; particles and high numbers of thrombocytes in the spleen, detected by TEM

Slight to moderate histiocytosis in the lung and

irregularities of olfactory epithelium remaining

Moderate histiocytosis in the lung and irregularities of olfactory epithelium remaining

Exacerbation towards a slight multifocal pulmonary inflammation

Full reversibility of splenetic effects; no pulmonary effects at any time point

No adverse findings

n.a.

No adverse findings

n.a.

No adverse findings

$$
\text { n.a. }
$$

No adverse findings

n.a.

No adverse findings n.a.

No adverse findings n.a.

No adverse findings n.a.

Lung: Particles in macrophages Partial regression of (recovery group: additionally mild histiocytosis)

\section{BALF effects; mild} diffuse or multifocal alveolar histiocytosis remaining

Lung: single or aggregated particle-loaded macrophages Partial regression of BALF effects; particle-loaded alveolar macrophages remaining 


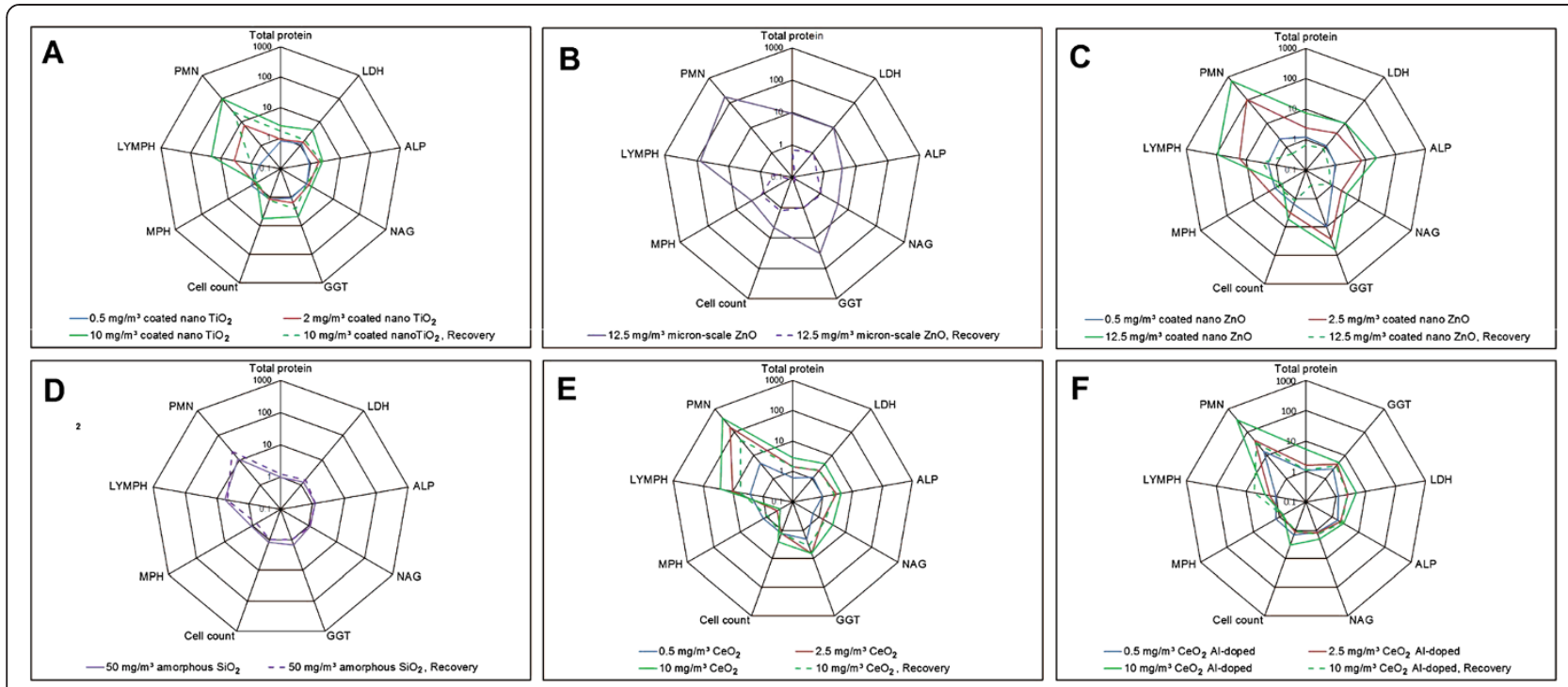

Figure 3 Comparison of changes in BALF. A: coated nano- $\mathrm{TiO}_{2}$. B: micron-scale $\mathrm{ZnO}$; $\mathbf{C}$ : coated nano- $\mathrm{ZnO}$; $\mathbf{D}$ : SiO 2 .naked; E: nano-CeO ; F: Al-doped nano- $\mathrm{CeO}_{2}$. Changes are shown as $\mathrm{X}$-fold differences compared to the corresponding control values using a logarithmic scaling.

counts, enzyme and total protein levels $24 \mathrm{~h}$ after the final exposure (i.e. in the exposure groups). Of note, cytokines and chemokines were not assessed for the coated nano- $\mathrm{TiO}_{2}$ test groups. Slight increases of a number of BALF parameters were also recorded for the rats of the mid test substance concentration group exposed to $2 \mathrm{mg} / \mathrm{m}^{3}$ coated nano- $\mathrm{TiO}_{2}$ (Table 3; Figure 3A; and Additional file 1: Table S1, Additional file 1: Table S2). Slightly increased BALF parameters were still observed three weeks post-exposure (i.e. in the recovery groups).

Histological examination of the lungs of the high concentration test group $\left(10 \mathrm{mg} / \mathrm{m}^{3}\right)$ revealed numerous pigment-loaded alveolar macrophages within the alveoli and slight diffuse histiocytosis, whereas the pulmonary epithelium appeared unchanged. No treatment-related effects were found in the upper airways (i.e. nasal cavity, larynx level, trachea, and carina) or in the mediastinal lymph nodes (Table 3; and Additional file 1: Table S1, Additional file 2: Table S10). Overall, coated nano- $\mathrm{TiO}_{2}$ caused mild pulmonary inflammation that was not fully reversible, with a NOAEC of $0.5 \mathrm{mg} / \mathrm{m}^{3}$. This finding is consistent with previous STIS data evaluating $\mathrm{TiO}_{2} \mathrm{P} 25$ [1].

\section{Micron-scale $\mathrm{ZnO}$ and coated nano-ZnO (NM-111)}

No clinical signs of toxicity, but markedly decreased body weight gain, were observed in the animal groups exposed to 2.5 and $12.5 \mathrm{mg} / \mathrm{m}^{3}$ coated nano- $\mathrm{ZnO}$ or $12.5 \mathrm{mg} / \mathrm{m}^{3}$ micron-scale $\mathrm{ZnO} 24 \mathrm{~h}$ after the final exposure. This effect was assessed as being a result of the systemic toxicity of released $\mathrm{Zn}^{2+}$ ions. Body weight gain returned to the control value at the end of the postexposure period (data not shown).
Hematology parameters, acute phase protein and cytokine levels in the blood were not affected in any of the $\mathrm{ZnO}$-treated rats. Increased absolute and relative lung weights (by approx. 30\%) were observed in animals exposed to micron-scale $\mathrm{ZnO}$ (data not shown).

Inhalation exposure to both coated nano- $\mathrm{ZnO}$ and micron-scale $\mathrm{ZnO}$ caused pulmonary inflammation, which was characterized by considerably increased PMN neutrophil and lymphocyte counts in the differential cell counts, and increased total cell counts in the BALF, which were dose-dependent for coated nano$\mathrm{ZnO}$ (Table 3; Figure 3B; and Additional file 1: Table S1, Additional file 1: Table S3) and accompanied by elevated BALF enzyme activities, total protein, and chemokine and cytokine concentrations. Regarding the latter, the levels of 25 and 26, respectively, of a total of 68 examined cell mediators examined (Additional file 1: Table S3) were significantly increased after the final exposure to $12.5 \mathrm{mg} / \mathrm{m}^{3}$ coated nano- $\mathrm{ZnO}$ or micronscale $\mathrm{ZnO}$. For coated nano- $\mathrm{ZnO}$, most parameters were also increased at $2.5 \mathrm{mg} / \mathrm{m}^{3}$. Even at the lowest aerosol concentration of $0.5 \mathrm{mg} / \mathrm{m}^{3}$ coated nano- $\mathrm{ZnO}$, the BALF enzyme glutamyltransferase (GGT), and the inflammatory mediators cytokine-induced neutrophil chemoattractant-1 (CINC-1; the rat homologue to interleukin (IL)-8), clusterin, and tissue inhibitor of metalloproteinases-1 (TIMP-1) were increased. Almost all BALF parameters returned to the respective levels of the control group after the 3-week post-exposure period. Overall, the pattern of changes was similar for both types of $\mathrm{ZnO}$, with stronger effects elicited by coated nano-ZnO (Table 3; and Additional file 1: Table S1, Additional file 1: Table S3). 
Histological examination of the lungs of the rats exposed to either micron-scale or coated nano- $\mathrm{ZnO}$ revealed pronounced PMN neutrophil, macrophage and lymphocyte infiltration (in accordance with the findings in the BALF), and a moderate multifocal rise in the number of alveolar macrophages, accompanied by an activation of the mediastinal lymph nodes. Most effects were fully reversible within the post-exposure period, after which only slight or moderate histiocytosis persisted in all animals. Overall, the histopathological effects caused by both substances were very similar, but compared to micron-scale $\mathrm{ZnO}$, coated nano- $\mathrm{ZnO}$ mediated effects were less severe or had a lower incidence (Table 3; and Additional file 1: Table S1, Additional file 2: Table S11).

In the upper respiratory tract, i.e. the nasal cavity, of all rats exposed to the $\mathrm{ZnO}$ materials multifocal necrosis of the olfactory epithelium was recorded that was moderate upon exposure to coated nano- $\mathrm{ZnO}$ and severe upon exposure to micron-scale $\mathrm{ZnO}$. In test groups treated with $12.5 \mathrm{mg} / \mathrm{m}^{3}$ micron-scale $\mathrm{ZnO}$ or coated nano- $\mathrm{ZnO}$, slight irregularities of the olfactory epithelium remained visible after the three-week exposure-free period (Table 3; and Additional file 1: Table S1, Additional file 2: Table S12).

In the animals exposed to coated nano- $\mathrm{ZnO}$ or micronscale $\mathrm{ZnO}$ increased cell proliferation in the terminal bronchioli were observed, which were concentrationdependent for coated nano-ZnO. Micron-scale $\mathrm{ZnO}$ also caused increased cell proliferation rates in the large bronchi and in the alveoli. In general, a higher proliferation rate was recorded after exposure to $12.5 \mathrm{mg} / \mathrm{m}^{3}$ micronscale $\mathrm{ZnO}$ than to the same concentration of coated nano- $\mathrm{ZnO}$ (Table 3; and Additional file 1: Table S1, Additional file 2: Table S13). Apoptosis was only observed in the test substance groups treated with $12.5 \mathrm{mg} / \mathrm{m}^{3}$ of micron-scale $\mathrm{ZnO}$ or coated nano- $\mathrm{ZnO}$ (data not shown).

Taking into account the changes in the BALF and the morphological findings in the lungs, mediastinal lymph nodes and nasal cavities, the NOAEC for coated nano$\mathrm{ZnO}$ was assessed as being $0.5 \mathrm{mg} / \mathrm{m}^{3}$. For micron-scale $\mathrm{ZnO}$, no NOAEC was set since it was only tested at one (high) concentration. Based upon the observed results, its NOAEC is likely to be in the same range as the one assessed for coated nano- $\mathrm{ZnO}$, since both materials induced similar effects. While alterations of BALF parameters were more pronounced for coated nano- $\mathrm{ZnO}$ than for micron-scale $\mathrm{ZnO}$, coated nano- $\mathrm{ZnO}$ elicited less pronounced adverse effects in the upper airways and only minor effects in regard to cell proliferation. These differences can most likely be explained by a reduced dissolution rate due to the coating of the nanoparticles. Similarly, coated nanosized $\mathrm{ZnO} \mathrm{NM}-111$ was slightly less toxic in rat precision-cut lung slices than uncoated nanosized $\mathrm{ZnO}$ (NM-110) [24].

\section{Amorphous silica-based materials}

Non-coated amorphous silica ( $\mathrm{SiO}_{2}$.naked) Inhalation exposure to an aerosol concentration of $50 \mathrm{mg} / \mathrm{m}^{3}$ naked amorphous silica caused marginal systemic inflammation, evidenced by slight and transient increases in granulocyte counts in the blood (data not shown). Increased PMN neutrophil and lymphocyte counts were present in the BALF of this high concentration test group shortly after exposure and (in the 10 and $50 \mathrm{mg} / \mathrm{m}^{3}$ test groups) 3 weeks post-exposure. Histologically, multifocal macrophage aggregates were observed in the lung shortly after exposure. This finding exacerbated towards a slight multifocal pulmonary inflammation by the end of the 3-week exposure free period (Table 3 ).

At concentrations up to $50 \mathrm{mg} / \mathrm{m}^{3}, \mathrm{SiO}_{2}$. naked did not induce any significant changes of BALF cytokines or chemokines in the exposure groups, i.e. those rats that were euthanized shortly after the final exposure, or in the recovery groups that were euthanized after the 3week post-exposure period (Additional file 1: Table S12). The NOAEC of $\mathrm{SiO}_{2}$. naked was assessed as being $2.5 \mathrm{mg} / \mathrm{m}^{3}$.

By comparison, Arts et al. [12] submitted three different synthetic amorphous silicas and quartz to a STIS with 3month post-exposure period. For all three amorphous silica, effects were observed at concentrations that were significantly lower than those from previously published studies investigating comparable substances or from the STIS performed within the present study: While only mild effects were observed in the BALF after exposure to 10 or $50 \mathrm{mg} / \mathrm{m}^{3}$ naked amorphous silica in the present study, marked effects were already detected after exposure to $25 \mathrm{mg} / \mathrm{m}^{3}$ of all three silicas investigated by Arts and coworkers [12]. These differences in toxicity can most likely be explained by differences in material properties.

\section{Polyacrylate-coated amorphous silica $\left(\mathrm{SiO}_{2}\right.$.acrylate)} Inhalation exposure to aerosol concentrations of up to $10 \mathrm{mg} / \mathrm{m}^{3}$ polyacrylate-coated amorphous silica did not lead to any biologically relevant changes of BALF parameters at any time point (Table 3; and Additional file 1: Table S1, Additional file 1: Table S4), nor were there any changes in hematology parameters or in the acute phase proteins in the blood. However, absolute spleen weights were increased by $37 \%$ and $30 \%$ in animals exposed to 2 and $10 \mathrm{mg} / \mathrm{m}^{3} \mathrm{SiO}_{2}$.acrylate, respectively, and their relative spleen weights were increased by $35 \%$ and $26 \%$, respectively. By contrast, the absolute and relative spleen weights of the recovery groups were comparable to the corresponding control values. The increased spleen weights of the exposure groups were assessed as 
compound-related since the inter-individual variation was small. No morphological changes were detected in the lung upon histopathological evaluation.

In following up the recorded alterations in spleen weights, the lungs and spleens from three animals, each, from the control and high concentration groups were investigated by transmission electron microscopy. In the lung, electron-dense aggregates consisting of small (approx. $20 \mathrm{~nm}$ ) particles were recorded in the alveolar space of the exposed animal with no corresponding findings in the control animals (images not shown). In the spleen of the animals treated with $10 \mathrm{mg} / \mathrm{m}^{3} \mathrm{SiO}_{2}$. acrylate, thrombocyte accumulations were observed (Figure 4B) whereas the spleens of the control animals were unaffected (Figure 4A). Additionally, the cytoplasm of the splenetic lymphocytes seemed to be less homogenous in the exposed animals (Figures $4 \mathrm{C}$ and 4D) than in the control animals (Figure 4E), and small electron-dense aggregates were found within the lymphocytic cytoplasm of the treated animals (Figures 4D and 4F). Since silicon particles were detected in the spleen (for details on the outcome of the organ burden analysis, c.f. Organ burden analysis), these morphological changes were assessed as being related to the test material, even though the physiological meaning of the findings in the spleen remains unclear.

Overall, the NOAEC for local effects in the respiratory tract was assessed as being at least $10 \mathrm{mg} / \mathrm{m}^{3}$. Taking into account the findings recorded for the spleen, the NOEC for systemic effects was $0.5 \mathrm{mg} / \mathrm{m}^{3}$.

Other surface-coated amorphous silica ( $\mathrm{SiO}_{2} . \mathrm{PEG}$, $\mathrm{SiO}_{2}$.phosphate, and $\mathrm{SiO}_{2}$.amino) No adverse effects were observed after inhalation exposure to the three silica particles surface-modified with polyethyleneglycol $\left(\mathrm{SiO}_{2}\right.$. PEG), phosphate $\left(\mathrm{SiO}_{2}\right.$.phosphate), or amino groups $\left(\mathrm{SiO}_{2}\right.$.amino) at concentrations up to $50 \mathrm{mg} / \mathrm{m}^{3}$ (Table 3; and Additional file 1: Table S1, Additional file 1: Table S4). Therefore the NOAEC for these compounds was assessed as being at least $50 \mathrm{mg} / \mathrm{m}^{3}$.

In comparing the effects elicited by the surface-coated silicas with those caused by naked amorphous silica, surface modifications apparently mask the toxicity of the core material.

\section{Barium sulfate ( $\mathrm{BaSO}_{4}$ )}

Nano- $\mathrm{BaSO}_{4}$ did not induce any treatment-related effects up to an aerosol concentration of $50 \mathrm{mg} / \mathrm{m}^{3}$ (Table 3; and Additional file 1: Table S1, Additional file 1: Table S5). Only in the tissue homogenates of the lavaged lungs, a transient increase in IL- $1 \alpha$ was observed that was assessed as not being biologically relevant. Therefore, the NOAEC for $\mathrm{BaSO}_{4}$ was determined as being at least $50 \mathrm{mg} / \mathrm{m}^{3}$. These results stand in line with a previous study investigating $\mathrm{BaSO}_{4}$ effects upon intratracheal instillation [25], where bolus doses of $4.8 \mathrm{mg}$ per rat lung did not affect any parameters of the BALF. Subchronic inhalation exposure to an even higher concentration $\left(75 \mathrm{mg} / \mathrm{m}^{3}\right)$ of micron-scale $\mathrm{BaSO}_{4}$, resulting in a lung burden of $5 \mathrm{mg} / \mathrm{lung}$, also did not result in increased PMN counts in the BALF [26]. Whereas the authors attributed this lack of effects to the small surface area of fine $\mathrm{BaSO}_{4}\left(3.13 \mathrm{~m}^{2} / \mathrm{g}\right)$, micron-scale $\mathrm{TiO}_{2}$ (with a similar surface area of $6 \mathrm{~m}^{2} / \mathrm{g}$ ) elicited pronounced increases of PMN neutrophils in the BALF in the same concentration range [27].

\section{Zirconium dioxide-based compounds}

Nano-zirconium dioxide (nano- $\mathrm{ZrO}_{2}$ ) Inhalation exposure to aerosol concentrations of up to $10 \mathrm{mg} / \mathrm{m}^{3}$ nano- $\mathrm{ZrO}_{2}$ did not induce any treatment-related effects in cytological, protein, enzyme, cytokine or chemokine levels in the BALF or in cytokine levels in the lung tissue (Table 3; and Additional file 1: Table S1, Additional file 1: Table S5), even though the comprehensive panel of 68 cell mediators was assessed both in the BALF and lung tissue (c.f. Summary of results). Likewise, the hematological parameters and acute phase protein levels in the blood remained unchanged. There were no histopathological changes of the respiratory tract, and cell proliferation rates and apoptotic reactions in lungs cells were comparable to those from the control groups (data not shown). Thus, the NOAEC for nano- $\mathrm{ZrO}_{2}$ was assessed as being $10 \mathrm{mg} / \mathrm{m}^{3}$.

This finding stands in line with human data for both $\mathrm{ZrSiO}_{4}$ and $\mathrm{ZrO}_{2}$. In an occupational setting, 32 hand finishers of zirconium metal, who were exposed to $5.75-14.7 \mathrm{mg} / \mathrm{m}^{3}$ of dust (25\% zirconium) over periods of 1-17 years, did not develop any exposurerelated symptoms [28]. Similarly, a study following up zirconium compound-exposed workers revealed that even long-lasting exposure of up to 20 years to peak concentrations up to $30 \mathrm{mg} / \mathrm{m}^{3}$ zirconium neither elicited abnormal chest radiographs, nor did it impair lung function parameters [29]. Hence, the lack of effects of nano- $\mathrm{ZrO}_{2}$ observed in the present study may be due to the very low intrinsic toxicity of this material.

Surface-coated zirconium dioxide $\left(\mathrm{ZrO}_{2}\right.$.TODA, and $\mathrm{ZrO}_{2}$.acrylate) No adverse effects were observed after inhalation exposure to the surface-coated zirconium dioxides $\mathrm{ZrO}_{2}$. TODA or $\mathrm{ZrO}_{2}$.acrylate at concentrations up to $50 \mathrm{mg} / \mathrm{m}^{3}$ (Table 3; and Additional file 1: Table S1, Additional file 1: Table S5). Under the conditions of the present study, the NOAEC for these compounds was therefore at least $50 \mathrm{mg} / \mathrm{m}^{3}$.

\section{Cerium dioxide-based materials}

Nano-cerium dioxide and Al-doped nano-cerium dioxide Overall, nanoform cerium dioxide (nano- $\mathrm{CeO}_{2}$ ) 
and Al-doped nano- $\mathrm{CeO}_{2}$ elicited similar effects with respect to BALF cytology and mediators.

At aerosol concentrations of $0.5 \mathrm{mg} / \mathrm{m}^{3}$ nano- $\mathrm{CeO}_{2}$, PMN neutrophil counts, total protein concentration and macrophage colony stimulating factor (M-CSF) levels were increased in the BALF. Inhalation exposure to 2.5 and $10 \mathrm{mg} / \mathrm{m}^{3}$ nano- $\mathrm{CeO}_{2}$ increased PMN neutrophil and lymphocyte counts in the BALF immediately after the final exposure, whereas macrophage counts were reduced in comparison to the corresponding control values (Table 3; Figures 3E and 3F; and Additional file 1: Table S1, Additional file 1: Table S6). Several enzyme activities (LDH, GGT, ALP) were increased in the BALF in the 2.5 and $10 \mathrm{mg} / \mathrm{m}^{3}$ exposure groups, whereas NAG activities and total protein levels were only increased at $10 \mathrm{mg} / \mathrm{m}^{3}$. Among the 68 antigens assessed in the BALF, the level of monocyte chemoattractant protein-1 (MCP1) was prominently increased (approx. 20- to 25-fold over the corresponding control values), while M-CSF and CINC-1 levels were only moderately elevated (below 10-fold). The macrophage markers macrophage-derived chemoattractant (MDC) and myeloperoxidase (MPO) were increased 360-fold and 115-fold, respectively. After the three-week post-exposure period, a partial regression of these effects was observed (Table 3; Figures $3 \mathrm{E}$ and 3F; and Additional file 1: Table S1, Additional file 1: Table S6).

Also in the lung tissue homogenates, of the 68 antigens assessed, 9 cytokines and chemokines (i.e. CINC-1/ IL-8; keratinocyte cytokine/growth-regulated oncogen- $\alpha$ (KC/GRO $\alpha$ ); MCP-1; MCP-3; M-CSF; MDC; macrophage inflammatory protein (MIP-1 $\alpha$ ); MIP-2; neutrophil gelatinase associated lipocalin (NGAL)) were significantly increased in the 2.5 and $10 \mathrm{mg} / \mathrm{m}^{3}$ nano$\mathrm{CeO}_{2}$ exposure groups, and increases only partially regressed within the post-exposure period (Additional file 1: Table S1, Additional file 1: Table S7).

Al-doped nano- $\mathrm{CeO}_{2}$ also induced significant increases in total cell counts, PMN neutrophil counts, and total protein concentration, and elevations in all enzymes tested. In the BALF, Al-doped nano- $\mathrm{CeO}_{2}$ further elicited higher concentrations of OPN than nano- $\mathrm{CeO}_{2}$, but lower levels of M-CSF, and, in the lung tissue, higher levels of IL- $1 \alpha$ (nano- $\mathrm{CeO}_{2}$ data for OPN and IL$1 \alpha$, being insignificant, not shown). The extent of partial regression of the elevated lung parameters was comparable in the recovery groups treated with either nano$\mathrm{CeO}_{2}$ or Al-doped $\mathrm{CeO}_{2}$ (Table 3; and SI, Additional file 1: Tables S8 and S9).

Hematology parameters and acute phase protein levels in the blood were not affected in rats treated with either $\mathrm{CeO}_{2}$ compound. Histological examination of the nano- $\mathrm{CeO}_{2}$ test groups revealed particles in alveolar macrophages in the exposure and recovery groups and, additionally, in the recovery groups, mild diffuse or multifocal alveolar histiocytosis. In the exposure groups treated with $\mathrm{Al}$-doped nano- $\mathrm{CeO}_{2}$, single or aggregated particle-loaded alveolar macrophages were observed that were still present after the post-exposure period, though less frequently (SI, Additional file 2: Tables S14 and S15). Cell proliferation rates and apoptosis in rats exposed to nano- $\mathrm{CeO}_{2}$ were comparable to the rates recorded in the corresponding control groups (data not shown).

Overall, inhaled nano- $\mathrm{CeO}_{2}$ and Al-doped nano- $\mathrm{CeO}_{2}$ caused a transient, concentration-dependent inflammation of the lung at all concentrations. Based upon the changes recorded in the BALF, the concentration-response curve of Al-doped $\mathrm{CeO}_{2}$ was steeper than the one calculated for nano- $\mathrm{CeO}_{2}$. In vitro studies with alveolar macrophages performed within the German NanoCare project determined a higher biological activity for Al-doped $\mathrm{CeO}_{2}$ than for nano- $\mathrm{CeO}_{2}$ [25], an observation that is in agreement with the in vivo STIS results of the present study. Taking into account the increased PMN neutrophil counts in the BALF, a NOAEC could not be established for nano- $\mathrm{CeO}_{2}$ or Al-doped nano- $\mathrm{CeO}_{2}\left(\mathrm{NOAEC}<0.5 \mathrm{mg} / \mathrm{m}^{3}\right)$.

These results stand in line with the outcome of a previous study investigating $\mathrm{CeO}_{2}$ effects upon intratracheal instillation of [16], showing that already bolus doses as low as $0.15 \mathrm{mg} / \mathrm{kg}$ body weight - corresponding to the low aerosol concentration of $0.5 \mathrm{mg} / \mathrm{m}^{3}$ applied in the present STIS - affected BALF parameters.

\section{Organ burden analysis}

The lungs (Table 4) and mediastinal lymph nodes (data not shown) were examined for the contents of the respective main element of the test material. For most test substances, the recorded pulmonary deposition was consistent with the expected deposition calculated making use of the Multiple Path Particle Dosimetry Model (MPPD software, version 2.11) [30,31]. The decrease in lung burden during the post-exposure period was around $20 \%$ for most test substances, reflecting a clearance rate with a half-life of about two months. For nano- $\mathrm{ZrO}_{2}, \mathrm{BaSO}_{4}$, the $\mathrm{SiO}_{2}$ test substances (apart from $\mathrm{SiO}_{2}$.acrylate), micron-scale $\mathrm{ZnO}$ and coated nano- $\mathrm{ZnO}$, the decrease rates were markedly higher: For nano$\mathrm{ZrO}_{2}$, decreases of up to $75 \%$ were observed. In animals exposed to $\mathrm{BaSO}_{4}$, the lung burden decreased by $77 \%$ during the three-week post-exposure period without notable increase of the substance in the lung-draining lymph nodes. Amorphous silica seemed to be cleared quickly as well: For naked amorphous silica, $\mathrm{SiO}_{2}$.PEG, and $\mathrm{SiO}_{2}$.amino, about 40 to $60 \%$ of the total deposition were cleared within 3 weeks. Unlike the PEG and amino coatings, however, the polyacrylate coating seemed to hamper the clearance rate of $\mathrm{SiO}_{2}$. The most pronounced decrease was recorded for those animals 
Table 4 Measured test substance deposition in the lung, expected deposition calculated by the Multiple Path Particle Dosimetry (MPPD) model, measured (absolute and relative) decrease of lung burden (clearance) after the recovery period

\begin{tabular}{|c|c|c|c|c|c|c|}
\hline Test substance & $\begin{array}{l}\text { Assumed } \\
100 \% \\
\text { deposition } \\
(\mathrm{mg})\end{array}$ & $\begin{array}{l}\text { (Lung burden) Measured } \\
\text { test material on study day } \\
5 \text { ( } \mu \mathrm{g} / \mathrm{lung})\end{array}$ & $\begin{array}{l}\text { Measured } \\
\text { deposition } \\
(\%)\end{array}$ & $\begin{array}{l}\text { Calculated } \\
\text { deposition } \\
(\%)\end{array}$ & $\begin{array}{l}\text { Measured lung } \\
\text { burden after } \\
\text { recovery period } \\
(\mu \mathrm{g} / \mathrm{lung})\end{array}$ & $\begin{array}{c}\% \text { Decrease of lung } \\
\text { burden after } \\
\text { recovery period }\end{array}$ \\
\hline $\begin{array}{l}\text { Coated nano- } \mathrm{TiO}_{2}\left(\mathrm{~T} \text {-lite } \mathrm{SF}^{\mathrm{TM}}\right. \\
\text { containing } 82 \% \mathrm{TiO}_{2} \text { and } \\
\left.10 \% \mathrm{Al}(\mathrm{OH})_{3}\right)\end{array}$ & 3.85 & $\begin{array}{c}459.0 \pm 71.3\left(\mathrm{TiO}_{2}\right) 49.1 \pm 7.6 \\
\left(\mathrm{Al}(\mathrm{OH})_{3}\right)\end{array}$ & $12.4 \%^{b}$ & $19.1 \%$ & $\begin{array}{c}467.4 \pm 43.4 \\
\left(\mathrm{TiO}_{2}\right) 46.3 \pm 5.0 \\
\left(\mathrm{Al}(\mathrm{OH})_{3}\right)\end{array}$ & $+1 \%$ \\
\hline \multirow[t]{2}{*}{ Micron-scale ZnO } & 5.508 & $82.3 \pm 12.5$ & $1.5 \%$ & $10.3 \%$ & $27.1 \pm 1.5$ & n.a. \\
\hline & 0.216 & $33.9 \pm 7.0$ & $15.7 \%$ & $12.4 \%$ & $25.4 \pm 1.3$ & n.a. \\
\hline \multirow[t]{2}{*}{$\begin{array}{l}\text { Coated nano-ZnO } \\
\text { (NM-111) }\end{array}$} & 1.008 & $123.4 \pm 28.4$ & $12.2 \%$ & $13.5 \%$ & $26.3 \pm 1.5$ & n.a. \\
\hline & 4.968 & $428.2 \pm 19.4$ & $8.6 \%$ & $13.4 \%$ & $28.4 \pm 4.1$ & n.a. \\
\hline \multirow[t]{2}{*}{$\mathrm{SiO}_{2}$.naked } & 18.936 & $342.3 \pm 10.7$ & $1.8 \%$ & $5.1 \%$ & $208.2 \pm 16.1$ & $-39 \%$ \\
\hline & 0.216 & $18.6 \pm 6.2$ & $8.6 \%$ & $7.1 \%$ & $15.7 \pm 6.9$ & $-16 \%$ \\
\hline \multirow[t]{3}{*}{$\mathrm{SiO}_{2}$.acrylate } & 0.756 & $37.1 \pm 6.9$ & $4.9 \%$ & $7.9 \%$ & $30.0 \pm 7.7$ & $-19 \%$ \\
\hline & 3.492 & $200.0 \pm 30.9$ & $5.7 \%$ & $6.8 \%$ & $132.1 \pm 43.3$ & $-34 \%$ \\
\hline & 0.738 & $59.2 \pm 11.0$ & $8.0 \%$ & $8.8 \%$ & $25.7 \pm 2.1$ & $-57 \%$ \\
\hline \multirow[t]{3}{*}{$\mathrm{SiO}_{2} \cdot \mathrm{PEG}$} & 3.60 & $182.6 \pm 27.1$ & $5.1 \%$ & $8.8 \%$ & $117.0 \pm 45.7$ & $-36 \%$ \\
\hline & 19.476 & $834.3 \pm 206.3$ & $4.3 \%$ & $6.5 \%$ & $370.8 \pm 40.5$ & $-56 \%$ \\
\hline & 1.044 & $71.3 \pm 11.0$ & $6.8 \%$ & $10.9 \%$ & $47.8 \pm 3.3$ & $-33 \%$ \\
\hline \multirow[t]{3}{*}{$\mathrm{SiO}_{2}$.phosphate } & 3.60 & $194.7 \pm 11.9$ & $5.4 \%$ & $6.1 \%$ & $104.8 \pm 21.4$ & $-46 \%$ \\
\hline & 18.54 & $499.2 \pm 30.9$ & $2.7 \%$ & $6.2 \%$ & $303.8 \pm 91.1$ & $-39 \%$ \\
\hline & 0.756 & $87.0 \pm 14.2$ & $11.5 \%$ & $10.5 \%$ & $52.1 \pm 9.6$ & $-41 \%$ \\
\hline \multirow[t]{2}{*}{$\mathrm{SiO}_{2}$.amino } & 3.672 & $295.9 \pm 81.7$ & $8.1 \%$ & $5.3 \%$ & $154.7 \pm 25.7$ & $-48 \%$ \\
\hline & 18.144 & $741.6 \pm 157.7$ & $4.1 \%$ & $5.4 \%$ & $474.2 \pm 155.1$ & $-36 \%$ \\
\hline \multirow[t]{2}{*}{ 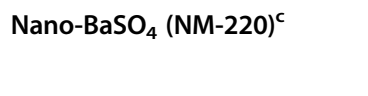 } & 19.224 & 1055.7 & $5.5 \%$ & $9.6 \%$ & 239.7 & $-77 \%$ \\
\hline & 0.18 & $18.0 \pm 5.6$ & $10.0 \%$ & $7.3 \%$ & $6.8 \pm 3.6$ & $-62 \%$ \\
\hline \multirow[t]{3}{*}{ Nano-ZrO ${ }_{2}$} & 0.936 & $20.3^{d} 117.5$ & $2.2 \% 12.6 \%$ & $8.2 \%$ & $29.3 \pm 6.2$ & $-75 \%$ \\
\hline & 3.456 & $270.6 \pm 28.9$ & $7.8 \%$ & $6.7 \%$ & $157.6 \pm 19.0$ & $-42 \%$ \\
\hline & 0.720 & $83.3 \pm 6.4$ & $11.6 \%$ & $10.9 \%$ & $41.9 \pm 5.4$ & $-50 \%$ \\
\hline \multirow[t]{3}{*}{$\mathrm{ZrO}_{2} \cdot \mathrm{TODA}$} & 3.816 & $233.2 \pm 6.9$ & $6.1 \%$ & $10.9 \%$ & $87.3 \pm 62.8$ & $-63 \%$ \\
\hline & 18.792 & $693.4 \pm 121.8$ & $3.7 \%$ & $7.7 \%$ & $520.5 \pm 82.0$ & $-25 \%$ \\
\hline & 0.684 & $7^{e}$ & $1.0 \%$ & $16.0 \%$ & LOQ & \\
\hline \multirow[t]{3}{*}{$\mathrm{ZrO}_{2}$.acrylate } & 3.636 & 70 & $1.9 \%$ & $11.1 \%$ & 49 & $-30 \%$ \\
\hline & 18.18 & 169 & $0.9 \%$ & $7.7 \%$ & 190 & $+12 \%$ \\
\hline & 0.277 & $52.0 \pm 5.0$ & $18.8 \%$ & $16.6 \%$ & $44.2 \pm 4.4$ & $-15 \%$ \\
\hline \multirow[t]{2}{*}{ Nano-scale $\mathrm{CeO}_{2}$} & 1.069 & $165.8 \pm 18.4$ & $15.5 \%$ & $14.3 \%$ & $157.6 \pm 18.7$ & $-5 \%$ \\
\hline & 4.176 & $417.6 \pm 44.3$ & $10.0 \%$ & $15.4 \%$ & $470.9 \pm 51.2$ & $+13 \%$ \\
\hline Al-doped nano-scale $\mathrm{CeO}_{2}{ }^{\mathrm{C}}$ & 3.312 & 326.8 & $7.8 \%$ & $6.8 \%$ & 304.7 & $-7 \%$ \\
\hline
\end{tabular}

n.a.: Not applicable: $\mathrm{Zn}$ content returned to control levels in all concentration groups. No relative decrease of lung burden was calculated due to high endogenous content of $\mathrm{Zn}$.

LOQ: limit of quantification.

${ }^{a}$ Recovery period for $\mathrm{SiO}_{2}$.acrylate was 14 days after the final exposure. For all other substances, the recovery period was 21 days.

${ }^{\mathrm{b}}$ Total amount of $\mathrm{TiO}_{2}$ and $\mathrm{Al}(\mathrm{OH})_{3}$ was assumed as total deposition.

'Only one rat was examined.

dOnly two samples were examined which differed considerably and hence are presented as individual animal data.

e Data for one animal, LOQ in the other two. 
exposed to nano- or micron-scale $\mathrm{ZnO}$ : After the postexposure period, the measured $\mathrm{Zn}$ content returned to the control level in all test groups. This observation can be explained by the dissolving properties of zinc oxide.

Overall, only very small amounts of the test substances were found in the lung-draining lymph nodes (data not shown). In animals exposed to either of the $\mathrm{ZrO}_{2}$ materials, zirconium was not detectable at any time point in any of the examined animals. In animals exposed to nano- $\mathrm{CeO}_{2}$ or Al-doped nano- $\mathrm{CeO}_{2}$, cerium levels were below the detection limit in the exposure groups. In the recovery group, they were 1.4, 2.5, and $4.1 \mu \mathrm{g}$ nano- $\mathrm{CeO}_{2}$, respectively, for the 3 examined rats exposed to $10 \mathrm{mg} / \mathrm{m}^{3}$ (effective concentration $11.6 \mathrm{mg} / \mathrm{m}^{3}$ ) of this test material, and $2.2 \mu \mathrm{g}$ for one animal treated with $10 \mathrm{mg} / \mathrm{m}^{3}$ (effective concentration $9.2 \mathrm{mg} / \mathrm{m}^{3}$ ) Al-doped $\mathrm{CeO}_{2}$. Similarly, barium was not detectable in the lymph nodes of the exposure groups and was only $1.4 \mu \mathrm{g}$ in the high concentration recovery group exposed to $50 \mathrm{mg} / \mathrm{m}^{3}$ $\mathrm{BaSO}_{4}$. Comparable amounts of zinc were found in the lung-draining lymph nodes regardless of the applied test concentration or the time point of assessment. Upon inhalation exposure to nano- $\mathrm{TiO}_{2}$, test substance translocation to the lung-draining lymph nodes was much lower than it had previously been observed after exposure to high concentrations of micron-scale $\mathrm{TiO}_{2}$ or quartz [27].

In those animals exposed to coated nano- $\mathrm{TiO}_{2}, \mathrm{BaSO}_{4}$, Al-doped $\mathrm{CeO}_{2}$, nano- or micron-scale $\mathrm{ZnO}$, the liver, kidneys, spleen, and brain (including the olfactory bulb) were also examined for the content of the respective main element, with a detection limit of $500 \mathrm{ng} /$ tissue sample (data not shown). In all organs evaluated, the titanium content was below this detection limit. Hence, there was no indication for test substance translocation upon inhalation exposure to coated nano- $\mathrm{TiO}_{2}$. The contents of barium or cerium detected in the liver, as the only extra-pulmonary organ, might be associated with $\mathrm{BaSO}_{4}$ or $\mathrm{CeO}_{2}$ dissolution in the body $[26,32]$. Also zinc oxide is known to be soluble in the body [33]. Therefore some degree of transport of zinc ions to peripheral organs was to be expected. Notwithstanding, the background level of $\mathrm{Zn}$ was high in all animals of the control group (20 $\mu \mathrm{g} / \mathrm{lung} ; 300 \mu \mathrm{g} / \mathrm{liver}$ ), and the $\mathrm{Zn}$ content determined in the organs of the animals treated with coated nano- $\mathrm{ZnO}$ and micron-scale $\mathrm{ZnO}$ was indistinguishable from the respective background levels determined in the control animals (data not shown).

As regards translocation of inhaled $\mathrm{SiO}_{2}$.acrylate to extra-pulmonary organs, small particle aggregates (60$80 \mathrm{~nm}$ ) were present in the cytoplasm of lymphocytes of the white pulp of rats exposed to $10 \mathrm{mg} / \mathrm{m}^{3} \mathrm{SiO}_{2}$.acrylate (as evidenced by TEM; Figures 4C, 4D, 4F; c.f. Amorphous silica-based materials). Using energy dispersed $\mathrm{x}$-ray spectroscopy (EDX), these particles were identified as being silicon-rich, whereas the surrounding cytoplasm contained only low background levels of silicon (Figure 4F).

\section{Summary of results}

In summary, the present study investigating the effects of 13 nanomaterials or micron-scale $\mathrm{ZnO}$ upon inhalation exposure to rats at aerosol concentrations of typically 0.5 to $50 \mathrm{mg} / \mathrm{m}^{3}$ for five consecutive days $(6 \mathrm{~h} /$ day $)$ revealed the following findings (Table 3):

- Eight nanomaterials $\left(\mathrm{BaSO}_{4}, \mathrm{SiO}_{2}\right.$.acrylate, $\mathrm{SiO}_{2} \cdot \mathrm{PEG}$, $\mathrm{SiO}_{2}$. phosphate, $\mathrm{SiO}_{2}$.amino, nano- $\mathrm{ZrO}_{2}, \mathrm{ZrO}_{2}$.TODA and $\mathrm{ZrO}_{2}$.acrylate) did not elicit effects on the rat lung, and their (local pulmonary) NOAECs were at least $50 \mathrm{mg} / \mathrm{m}^{3}$ (or at least $10 \mathrm{mg} / \mathrm{m}^{3}$ if this was the highest concentration tested).

- $\mathrm{SiO}_{2}$.naked, multifocal macrophage aggregates were observed in the respiratory tract immediately after the exposure period that exacerbated towards a slight multifocal inflammation during the 3-week post-exposure period. Its NOAEC was $2.5 \mathrm{mg} / \mathrm{m}^{3}$.

- Four nanomaterials (coated nano- $\mathrm{TiO}_{2}$, coated nano$\mathrm{ZnO}$, nano- $\mathrm{CeO}_{2}$, Al-doped nano- $\mathrm{CeO}_{2}$ ) evoked transient and concentration-dependent pulmonary inflammatory reactions that were only partially reversible during the two- or three-week post-exposure period. Their NOAEC was $0.5 \mathrm{mg} / \mathrm{m}^{3}$ or below. The same applies to micron-scale $\mathrm{ZnO}$, for which, however, no NOAEC was laid down since it was only tested at one (high) test substance concentration.

- Observed extra-pulmonary effects, immediately after the final exposure, were the splenetic alterations recorded for $\mathrm{SiO}_{2}$.acrylate (for which therefore a systemic NOEC was set at $0.5 \mathrm{mg} / \mathrm{m}^{3}$ ) and the moderate to severe necrosis of the olfactory epithelium recorded for micron-scale $\mathrm{ZnO}$ and coated nano- $\mathrm{ZnO}$. These splenetic effects were fully reversible within the postexposure period, and the nasal cavity alterations partially reversible.

\section{Discussion}

In 2009, the short-term inhalation study protocol (STIS) was established to fulfil the urgent need for a rapid and reliable method to evaluate the pulmonary toxicity of nanomaterials [1]. The protocol was based on the hypothesis that a nanomaterial's toxicity (1) is initiated by its inflammatory potential and (2) is influenced by its deposition and translocation in the body and its clearance therefrom. Both aspects can be determined after a relatively short exposure period when including specific investigations of the animals. Meanwhile, more than 20 industrially relevant nanomaterials have been tested in the STIS, covering the 13 nanomaterials presented in 
this study, four carbon-based nanomaterials [34,35], two cadmium-based quantum dots [36,37], one polyacrylate [38], and one pigment [Ma-Hock and co-workers, unpublished observations]. In the following section, the experiences gained with all STIS conducted so far are assessed with the aim of re-evaluating the study design of the STIS and of determining its relevance in predicting nanomaterial effects that develop upon subchronic or chronic exposure.

\section{Study protocol}

The study design for the current STIS was first endorsed based on an evaluation of an extensive data set for nano- $\mathrm{TiO}_{2}$ [1]. Since then, the key elements of the study design have remained unchanged, i.e.:

- Male Wistar rats;

- Head-nose inhalation exposure;

- Exposure for six hours a day on five consecutive days;

- Histological examination and bronchoalveolar lavage;

- Post-exposure period of three weeks.

With regard to histological examination, experience has shown that it is essential to evaluate the entire respiratory tract. First of all, lavage parameters only reveal pulmonary effects. Hence, effects occurring in the upper respiratory tract might be missed without histological examination. Coated nano- $\mathrm{ZnO}$ and micron-scale $\mathrm{ZnO}$ are examples for substances affecting the upper respiratory tract. Additionally, classical BALF parameters are general indicators of acute inflammatory reactions, which are not necessarily associated to a specific type of morphological change. For all of the above-mentioned nanomaterials tested in the STIS so far, the pattern of BALF changes has been similar: The number of PMN neutrophils was the most sensitive parameter and was accompanied by increases of other BALF cells, increased BALF total protein concentrations and increased enzyme activities. Notwithstanding these very similar BALF findings, the spectrum of different nanomaterials investigated elicited clear differences in morphological changes of the lung tissue, to name multiwall carbon nanotubes (MWCNTs) as a prominent example $[34,35]$. Consequently, histological examination of the entire respiratory tract should be an integral part of the STIS protocol.

In in vitro studies, pro-inflammatory cytokines are being widely applied as indicators of acute or on-going inflammation or inflammation-like responses. Additionally, pro-fibrotic cytokines, such as transforming growth factor (TGF)- $\beta 1$, M-CSF, or OPN, may be useful in identifying particle-induced fibrotic or neoplastic changes already at very early pathogenic stages. Aiming at recognizing appropriate markers for in vivo studies, such as the STIS, almost 70 different cytokines, chemokines and inflammation-relevant enzymes from the BALF and lung tissue homogenates have been screened in the course of the development of the STIS. Of these mediators, only a limited panel appear to be relevant for the assessment of particle effects in the lungs. Specifically, 4 mediators, i.e. MCP-1, CINC/IL8, M-CSF and OPN, were selected as being most meaningful for the detection of substance-induced pulmonary reactions in the BALF.

MCP-1 and CINC-1/IL-8, both of which are released by epithelial cells and, to a certain extent, also by macrophages, reached considerable concentrations in the BALF upon particle treatment. MCP-1 is a C-C cytokine that strongly attracts blood monocytes and lymphocytes to the alveolar compartment [39]. CINC-1, the rat homologue to IL-8, is a pro-inflammatory C-X-C chemokine that exhibits neutrophil chemotactic activity [40]. Dose-dependent increases of MCP-1 and CINC-1/ IL-8 in the BALF were recorded upon inhalation exposure to nano- $\mathrm{CeO}_{2}$, Al-doped nano- $\mathrm{CeO}_{2}$, coated nano$\mathrm{ZnO}$, or micron-scale $\mathrm{ZnO}$. Apart from the dose groups treated with coated nano- $\mathrm{ZnO}$, the increases in $\mathrm{MCP}-1$ exceeded those of CINC-1/IL-8.

Reporting increased IL-8 expression in human A549 alveolar epithelial cells upon exposure to micron-scale $\mathrm{BaSO}_{4}$ (and similar observations published by Tran et al. [13]), Donaldson et al. [40] suggested IL-8 induction as being a relevant parameter for the validation of in vitro assays. However, in contrast to the observations made by Donaldson and co-workers, in the present study, up to $50 \mathrm{mg} / \mathrm{m}^{3}$ nano- $\mathrm{BaSO}_{4}$ did not lead to any biologically relevant cytokine induction. This discrepancy might be explained by differences of the $\mathrm{BaSO}_{4}$ materials or by deviating experimental regimes. Nevertheless, it should be followed up in further studies aiming at correlating in vivo responses to in vitro IL-8 production in epithelial cells. Regardless of any possible in vitro-in vivo discrepancies, both MCP-1 and CINC/IL-8 displayed a large dynamic range in the present study, and hence were assessed as suitable markers for early pulmonary inflammation and macrophage recruitment to the lungs.

M-CSF is a cytokine produced by macrophages that is involved in the differentiation of monocytes into histiocytes or, in conjunction with other factors, in the differentiation of osteoclasts [41]. At least in mice, its overexpression has been associated with glycolipid-induced granulomas [42], and M-CSF might possibly induce an increase in the number of alveolar macrophages. In the present study, M-CSF levels were not elevated upon exposure to nano- $\mathrm{BaSO}_{4}$, or polyacrylate-coated amorphous silica, while pronounced M-CSF increases were elicited by coated nano- $\mathrm{ZnO}$ and micron-scale $\mathrm{ZnO}$, and nano- $\mathrm{CeO}_{2}$. However, the M-CSF concentrations in the 
BALF did not correlate with macrophage counts in the BALF, presumably due to the lavage technique used, allowing only small fractions of alveolar macrophages to be washed out.

OPN is an arginine-glycine-aspartic acid (RGD)-containing protein occurring not only in the extracellular matrix of mineralized tissues, but also as a cytokine in body fluids [43]. OPN transcription is, among others, stimulated by IL- 1 and/or TNF- $\alpha$. As a cytokine, OPN has both pro- and anti-inflammatory properties. With respect to the latter, it inhibits production of nitric oxide (NO) and down-regulates inducible NO synthase [44]. More specifically, OPN has been described to be involved in pulmonary granuloma formation in rodents $[45,46]$. In rats exposed subchronically to $50 \mathrm{mg} / \mathrm{m}^{3}$ micron-scale $\mathrm{TiO}_{2}$, a concentration eliciting lung inflammation and fibrosis [7], immediate and sustained formation of OPN was observed. These and other results strongly suggest that OPN is a useful biomarker for fibro-proliferative lung disease in rodents and humans [47].

In the present study, OPN was increased up to 10 -fold directly after inhalation of nano- $\mathrm{CeO}_{2}$, coated nano$\mathrm{ZnO}$, and micron-scale $\mathrm{ZnO}$. In all of these cases, OPN increases were transient, and they were accompanied by elevations of other pro-inflammatory cytokines, such as MCP-1 or IL-1 $\alpha$. Even though the corresponding histological examinations revealed no signs of beginning granulomatous changes or fibrosis, Cho and co-workers [9] recorded the development of granulomas and deposition of fibrotic tissue, respectively, upon instillation of $\mathrm{CeO}_{2}$ or $\mathrm{ZnO}$ nanoparticles. By contrast, the slight increase in OPN observed after the three-week postexposure period in the recovery group treated with $\mathrm{SiO}_{2}$. naked was not accompanied by changes in any other cytokines and, therefore, was assessed as being arbitrary.

Aiming at supplementing evaluation of the BALF, the added value of determining TNF- $\boldsymbol{\alpha}$ and IL-1 $\boldsymbol{\alpha}$ as lung tissue homogenate parameters was assessed. TNF- $\alpha$ and IL- $1 \alpha$ are pro-inflammatory cytokines released by activated macrophages and other immune cells. By autocrine and/or paracrine pathways, they can stimulate release of further chemokines from other macrophages or epithelial cells [48-50]. TNF- $\alpha$ is a pleiotropic cytokine and a strong chemoattractant for PMN neutrophils $[50,51]$. Therefore it contributes to the early PMN neutrophilic infiltration and eosinophil recruitment into the airways, and it further increases alveolar capillary permeability $[51,52]$. In previously performed STIS, both IL- $1 \alpha$ and TNF- $\alpha$ were found in higher concentrations in lung tissue homogenates than in the BALF. This may be explained by IL- $1 \alpha$ also being synthesized by epithelial and endothelial cells and/or by the observation that approximately $80 \%$ of the pulmonary macrophages remain in the lung after the first lavage [53]. In all STIS performed in the course of the present study, only small and inconsistent increases in TNF- $\alpha$ or IL$1 \alpha$ levels were observed in the BALF or lung tissue homogenates, and these minor changes were found to add only limited information to the understanding of substance-induced early inflammatory processes occurring in the lung.

Similarly, also the assessment of cell proliferation rates or apoptosis in the large and medium bronchi, terminal bronchioli, or alveoli did not provide substantial added value information for the toxicological assessment of the test materials investigated in the present study.

\section{Correlation of the STIS with chronic or subchronic inhalation studies}

In an extensive case report by Klein and co-authors [3], the results of all STIS that were available at the time of writing in 2012 were compared to the results of subchronic and chronic inhalation studies of the same or similar materials. The review also included the overall results of a few of the STIS presented and discussed in detail in the study at hand. The list of materials assessed by Klein and co-authors comprises commercially relevant nanomaterials and selected non-nanoform reference materials, i.e. quartz, pigmentary and nanosized $\mathrm{TiO}_{2}$, synthetic amorphous silica, zinc oxide, zirconium dioxide, and multiwall carbon nanotubes. The studies included in the case report were not identical in regard to experimental conditions, such as animal strains, physico-chemical characteristics of the test materials, or preparation of the test material. Furthermore, only a limited number of subchronic and chronic studies were available against which to compare the results of the STIS. Nevertheless, the ranking of the spectrum of nanomaterials in regard to their potential to induce adverse effects was concordant for the NOAECs determined in the STIS and in the corresponding subchronic and chronic studies, and it was also consistent with the ranking set up in the present study. Furthermore, the STIS were able to reveal the progression or regression of adverse effects, to indicate translocation of materials to extra-pulmonary organs and to provide early indications of effects that only develop over time and hence only become fully pronounced in longer-term studies [3].

Overall, the STIS is able to detect early effects that mostly reflect inflammation, and/or beginning histological changes, while a meaningful comparison of subchronic toxicity endpoints, such as fibrosis and cancer, to STIS parameters is hardly possible. Nevertheless, sustained inflammation is being suspected to be a necessary, though not sufficient, prerequisite for enhanced reactive oxygen species (ROS) formation, fibrosis and even cancer, at least in the rat lung [54]. 
Therefore, an estimation of inflammatory effects at an early stage (directly after the final exposure or two days thereafter) combined with data on reversibility of the effects (three weeks post-exposure) may be used as an indicator for the severity of toxic effects.

Taking into account all of these considerations, the STIS is assessed as a suitable test method to be applied as a versatile first step in a tiered testing approach. As an early tier test, the STIS enables prioritizing nanomaterials for further testing and allows selecting appropriate testing strategies for the given test substance, which may, or may not, include subchronic or chronic tests. In the report of the NanoSafety Cluster Working Group 10, application of a targeted strategy for the testing and assessment of nanomaterials was encouraged, and the STIS was suggested as a basic test for Tier 2, i.e. the first tier requiring testing, upon collection of all available information in Tier 1 [55].

\section{Application of the STIS data for the grouping of nanomaterials}

The STIS provides information on the lung burden, test substance translocation to extra-pulmonary organs, as well as the type and potency of effects in the lung and in other tissues together with the persistence of these effects. Making use of these elements of the STIS protocol, the 14 materials (13 nanomaterials) assessed in the present study can be grouped in accordance to (1) the potency of pulmonary inflammation; (2) the affection of extra-pulmonary organs; (3) the reversibility or persistence of effects.

\section{Nanomaterial grouping based on the potency of lung inflammation}

Based on the pulmonary effects observed at different aerosol concentrations in the STIS, the test materials evaluated in the present study (and in previously performed STIS) can be assigned to four different potency groups (Figure 5):

- Substances causing no lung effects in the STIS up to aerosol concentrations of $50 \mathrm{mg} / \mathrm{m}^{3}$, i.e. $\mathrm{SiO}_{2}$.PEG, $\mathrm{SiO}_{2}$. phosphate, $\mathrm{SiO}_{2}$. amino, $\mathrm{BaSO}_{4}$, nano- $\mathrm{ZrO}_{2}$, $\mathrm{ZrO}_{2}$.TODA, $\mathrm{ZrO}_{2}$.acrylate. In further STIS, graphite nanoplatelets and carbon black did not induce any adverse effects up to the highest test concentration $10 \mathrm{mg} / \mathrm{m}^{3}$ [35]. $\mathrm{SiO}_{2}$. acrylate did not cause any pulmonary effects up to the highest concentration of $10 \mathrm{mg} / \mathrm{m}^{3}$, but it did elicit splenetic effects at $2 \mathrm{mg} / \mathrm{m}^{3}$ and above, so that a systemic NOEC of $0.5 \mathrm{mg} / \mathrm{m}^{3}$ was determined for this substance.
- Substances causing lung effects in the STIS at aerosol concentrations at $2.5 \mathrm{mg} / \mathrm{m}^{3}$, i.e. precipitated naked amorphous silica;

- Substances causing lung effects in the STIS at aerosol concentrations of approximately $0.5 \mathrm{mg} / \mathrm{m}^{3}$, i.e. uncoated nano- $\mathrm{TiO}_{2}[1]$, coated nano- $\mathrm{TiO}_{2}$, $\mathrm{ZnO}$, coated nano- $\mathrm{ZnO}$, nano- $\mathrm{CeO}_{2}$, Al-doped nano- $\mathrm{CeO}_{2}$;

- Materials causing lung effects in STIS at approximately $0.1 \mathrm{mg} / \mathrm{m}^{3}$ : None of the 14 test materials applied in the present study was tested at such low aerosol concentrations, since they were not expected to possess a very high toxic potency. For MWCNTs, however, a NOAEC at or below $0.1 \mathrm{mg} / \mathrm{m}^{3}$ was calculated in a STIS, and this very low value was subsequently confirmed in two unrelated subchronic inhalation studies $[35,56]$.

Of note, this STIS-based potency ranking is largely consistent with a banding scheme suggested by the US National Institute for Occupational Safety and Health (NIOSH) [59].

Based on the toxic potency information obtained in the STIS, $\mathrm{CeO}_{2}$ and $\mathrm{BaSO}_{4}$ nanomaterials were selected for 2-year combined chronic toxicity/carcinogenicity inhalation studies that are still ongoing (OECD TG 453).

\section{Nanomaterial grouping based on affected extra-pulmonary organs}

Of the 13 nanomaterials tested in the STIS in the present study, only two caused effects outside the lung. These were the same materials that were also detected in extra-pulmonary tissues, i.e. polyacrylate-coated $\mathrm{SiO}_{2}$ and coated nano- $\mathrm{ZnO}$. Inhalation of $\mathrm{SiO}_{2}$. acrylate resulted in enlarged spleens, and $\mathrm{ZnO}$ caused damage of the upper airways. These findings confirm the value of collecting tissue burden data, and affection of extrapulmonary organs may also (and correspondingly) be used as a parameter for grouping and testing strategies. Based upon the results of the STIS, further testing of these materials should include effects on target organs.

\section{Nanomaterial grouping based on the reversibility or persistence of effects}

The pulmonary effects observed upon rat 5-day inhalation exposure to coated nano- $\mathrm{TiO}_{2}$ or the $\mathrm{ZnO}$ and $\mathrm{CeO}_{2}$ compounds were not fully reversible within the three-week post-exposure period, whereas the systemic effects caused by polyacrylate-coated $\mathrm{SiO}_{2}$ were no longer observed after this period. One reason for effects being only partially regressive might be that the threeweek post-exposure period was not sufficiently long to allow full recovery to take place, such as is most likely the case for the soluble $\mathrm{ZnO}$ materials. Particle solubility 
presumably is an important factor determining reversibility of effects. Consequently, e.g., amorphous silica nanomaterials having some (low) degree of solubility would be less prone to elicit long-term effects than $\mathrm{TiO}_{2}$ nanomaterials for which particle dissolution has not been recorded.

Alternatively, partial regression of effects might be an indication that the development of chronic effects cannot be excluded, especially if the lung clearance mechanism is overloaded. Such specifications obviously provide valuable information for the design of further investigations of these substances. Moreover, information on the reversibility or persistence of effects, combined with substance pulmonary clearance rates, can be used as a grouping criterion for hazard assessments addressing short-term exposure scenarios. Likewise, progressive pulmonary alterations, such as fibrosis upon inhalation exposure to quartz or the formation of granuloma upon exposure to MWCNTs $[34,35]$, fall into this category.

\section{Conclusion}

Short-term inhalation studies with aerosols generated from 14 particulate materials (1 micron-scale and 13 nanomaterials) provided information on the biokinetics and pulmonary and extra-pulmonary effects of the test materials. It further allowed ranking the materials in regard to their potency based upon NOAECs that were derived from well-quantifiable parameters, such as PMN neutrophil counts or total protein concentrations in the BALF, or from the incidence and severity of histological findings (Figure 5).

A number of the test materials did not elicit adverse pulmonary effects under the experimental conditions of the present study, i.e. $\mathrm{BaSO}_{4}$, all $\mathrm{ZrO}_{2}$ materials and the surface-functionalized $\mathrm{SiO}_{2}$ materials. With the exception of $\mathrm{SiO}_{2}$.acrylate, also no systemic effects were observed for these substances. Hence, the outcome of the present study points to the low pulmonary toxicity of these nanomaterials upon inhalation.

Apart from serving to reveal a substance's toxic potency, information on the type, location and reversibility of the observed effects can be used to guide further testing, e.g. in regard to those materials for which adverse pulmonary effects (nano- $\mathrm{TiO}_{2}$, both $\mathrm{CeO}_{2}$ nanomaterials and $\mathrm{SiO}_{2}$.naked) or adverse extra-pulmonary effects (both $\mathrm{ZnO}$ materials and $\mathrm{SiO}_{2}$.acrylate) were observed.

Additionally, the results from the STIS can be used for the grouping of nanomaterials for safety assessment. It is increasingly being recognized that it is not possible to relate biological effects elicited by nanomaterials to one single material property and that other forms of grouping might be more relevant in predicting nanomaterial effects [55,59]. Groups of nanomaterials with similar toxicity can be defined based upon similarities in biological activities, lung tissue burden or translocation to extra-pulmonary tissues, rather than merely referring to the materials' properties. In this context, the STIS data published so far provide a large database on effects upon inhalation exposure to nanomaterials that can serve to foster the understanding of material properties, which are attributable to toxic effects of nanoparticles.

Based upon the overall outcome of the present study, the STIS is suggested as an early tier test in an integrated approach to the testing and assessment of nanomaterials. As the comparison of the outcome of the STIS with results from subchronic and chronic inhalation studies has revealed, the STIS may well be suited in reducing the need for such longer-term studies. Furthermore, the STIS may be supplemented or even replaced by appropriate in vitro methods once they become available. In this respect, STIS data will contribute to the development and validation of such in vitro methods, thereby directly serving the 3Rs principle to refine, reduce, and, ultimately, replace animal testing as first described by Russell and Burch in 1959 [60] and laid down as legal provision in the European Directive 2010/63/EU on the use of animals for scientific purposes [61].

\section{Material and methods}

\section{Test materials}

As presented in Table 1, the characterization of the material properties included particle size distribution - in the dry state and in relevant media; state of agglomeration or aggregation, water solubility and dispersability, crystalline phase, crystallite size, specific surface area, zeta potential (surface charge), surface chemistry (where appropriate), photocatalytic activity and porosity. The applied characterization methods have previously been described in detail together with a discussion of the results of the physico-chemical characterization for the powders [22] and the nanoGEM project suspensions [23] (Table 5).

\section{Aerosol generation and monitoring}

Liquid nanomaterial dispersions were delivered at a constant rate into an atomizer and aerosolized by compressed air. For solid materials, dust aerosols were produced by dry dispersion of powder pellets with a brush dust generator (developed by the Technical University of Karlsruhe, Germany, in cooperation with BASF, Germany). The different target concentrations were achieved by adjustment of the feeding speed of the substance pellet and the rotation speed of the brush. Aerosols were generated with compressed air and diluted with conditioned air. The aerosols were passed via a cyclone (to separate particles $>3 \mu \mathrm{m}$ ) into the head-nose inhalation system. 
Table 5 Study design

\begin{tabular}{|c|c|c|c|c|c|c|}
\hline $\begin{array}{l}\text { Test substance } \\
\text { Study element/part }\end{array}$ & $\begin{array}{c}\text { Coated } \\
\text { nano-TiO }\end{array}$ & $\begin{array}{l}\mathrm{SiO}_{2} \\
\text { acrylate }\end{array}$ & $\begin{array}{l}\text { Micron-scale } \mathrm{ZnO} ; \\
\text { Coated nano-ZnO } \\
\text { (NM-111) }\end{array}$ & $\begin{array}{l}\text { Nano- } \mathrm{CeO}_{2} ; \\
\text { Nano- } \mathrm{ZrO}_{2}\end{array}$ & $\begin{array}{c}\mathrm{SiO}_{2} \cdot \text { naked; } \mathrm{BaSO}_{4} \\
\text { (NM-220); } \\
\text { Al-doped nano-CeO }\end{array}$ & $\begin{array}{c}\mathrm{SiO}_{2} . \mathrm{PEG} ; \mathrm{SiO}_{2} . \\
\text { phosphate; } \\
\mathrm{SiO}_{2} \cdot \text { amino; } \mathrm{ZrO}_{2} . \mathrm{TODA} ; \\
\mathrm{ZrO}_{2} \cdot \text { acrylate }\end{array}$ \\
\hline Recovery period & 21 & 14 & 21 & 21 & 21 & 21 \\
\hline $\begin{array}{l}\text { Necropsy and histology of } \\
\text { respiratory tract }\end{array}$ & $\sqrt{ }^{\mathrm{a}}$ & $\sqrt{ }^{\mathrm{b}}$ & $\sqrt{ }^{\mathrm{b}}$ & $\sqrt{ }^{\mathrm{b}}$ & $\sqrt{ }^{c}$ & $\sqrt{ }^{\mathrm{a}}$ \\
\hline Histology of brain & n.d. & $\sqrt{ }^{\mathrm{b}}$ & $\sqrt{ }^{\mathrm{b}}$ & $\sqrt{ }^{\mathrm{b}}$ & n.d. & $\sqrt{ }^{\mathrm{a}}$ \\
\hline $\begin{array}{l}\text { Cell proliferation and } \\
\text { apoptosis }\end{array}$ & n.d. & n.d. & $\sqrt{ }^{\mathrm{b}}$ & $\sqrt{ }^{\mathrm{b}}$ & n.d. & n.d. \\
\hline Electron microscopy & n.d. & $V^{a}$ & n.d. & n.d. & n.d. & n.d. \\
\hline $\begin{array}{l}\text { BALF cytology, protein and } \\
\text { enzyme activities }^{d}\end{array}$ & $\sqrt{ }$ & $\sqrt{ }$ & $\sqrt{ }$ & $\sqrt{ }$ & $\sqrt{ }$ & $\sqrt{ }$ \\
\hline $\begin{array}{l}\text { BALF cytokines and } \\
\text { chemokines }^{d}\end{array}$ & n.d. & $\begin{array}{l}\text { M-CSF, } \\
\text { TGF- } \beta \text {, } \\
\text { MIP-2, } \\
\text { MCP-1, } \\
\text { IL-1a }\end{array}$ & $\begin{array}{c}68 \text { cytokines, } \\
\text { chemokines and } \\
\text { inflammation-relevant } \\
\text { hormones and } \\
\text { enzymes }\end{array}$ & $\begin{array}{c}68 \text { cytokines, } \\
\text { chemokines and } \\
\text { inflammation-relevant } \\
\text { hormones and } \\
\text { enzymes }\end{array}$ & $\begin{array}{c}\text { Clusterin; MCP-1; } \\
\text { CINC-1/IL-8; M-CSF; } \\
\text { OPN }\end{array}$ & $\begin{array}{c}\text { MCP-1; CINC-1 /IL-8; } \\
\text { M-CSF; OPN }\end{array}$ \\
\hline $\begin{array}{l}\text { Cytokines and chemokines } \\
\text { in lavaged lung tissue } \mathrm{d}^{\mathrm{d}}\end{array}$ & n.d. & n.d. & n.d. & $\begin{array}{c}68 \text { cytokines, } \\
\text { chemokines and } \\
\text { inflammation-relevant } \\
\text { hormones and } \\
\text { enzymes }\end{array}$ & IL-1 a TNF-a & IL-1aTNF-a \\
\hline $\begin{array}{l}\text { Hematology according to } \\
\text { OECD TG 412; c-reactive } \\
\text { protein and haptoglobin }\end{array}$ & n.d. & $\sqrt{ }$ & $\sqrt{ }$ & $\sqrt{ }$ & $\sqrt{ }$ & $\sqrt{ }$ \\
\hline Organ burden ${ }^{a, f}$ & $\sqrt{ }$ & $\sqrt{ }$ & $\sqrt{ }$ & $\sqrt{ }$ & $\sqrt{ }$ & $\sqrt{ }$ \\
\hline
\end{tabular}

n.d.: not determined.

${ }^{a}$ For these investigations, altogether 3 animals per concentration and time point were used.

${ }^{b}$ For these investigations, altogether 6 animals per concentration and time point were used.

${ }^{c}$ For this investigations, 3 animals per concentration and time point were used in the $\mathrm{BaSO}_{4}$ and Al-doped $\mathrm{CeO}_{2}$ test runs, whereas 6 animals per concentration and time point were used in the $\mathrm{SiO}_{2}$.naked test run.

${ }^{d}$ For these investigations, altogether 5 animals per concentration and time point were used.

${ }^{e}$ c.f. Evaluation of bronchoalveolar lavage fluid (BALF) and lung tissue homogenates.

${ }^{f}$ For all test materials, tissue contents of the respective main element were determined in the lung and lung-associated mediastinal lymph nodes. For coated nano- $\mathrm{TiO}_{2}, \mathrm{BaSO}_{4}, \mathrm{Al}$-doped $\mathrm{CeO}_{2}$, nano- and micron-scale $\mathrm{ZnO}$, additionally, organ burden of the extra-pulmonary organs was assessed.

Abbreviations: CINC-1/IL-8 cytokine-induced neutrophil chemoattractant-1, the rat homologue to IL-8, IL interleukin, $M$-CSF macrophage colony stimulating factor, $M C P$, monocyte chemoattractant protein, MIP macrophage inflammatory protein, OPN osteopontin, TNF- $a$ tumor necrosis factor-a.

To reduce electrostatic charging, brushes made of stainless steel were used, and the generator itself and all conducting tubes were grounded [57,62].

The atmospheric concentration of the aerosols and the aerodynamic particle diameter (cascade impactor analysis) were determined by gravimetric measurement using a sampling probe with a diameter of $7 \mathrm{~mm}$. In general, the sampling velocity was adjusted to $1.25 \mathrm{~m} / \mathrm{s}$, and the sampling flow rate was $3 \mathrm{~L} / \mathrm{min}$. Under these conditions, the sampling error due to an-isokinetic sampling is considered to be negligible [62].

To determine the atmospheric aerosol concentration, a sampling device (Millipore) equipped with glass fibre filters (Macherey-Nagel, Düren, Germany, type MN 85/ $90 \mathrm{BF}, \mathrm{d}=4.7 \mathrm{~cm}$ ) was used. Sampling was performed adjacent to the location where the animals' noses were positioned in the exposure system. Depending on the respective atmospheric concentrations, the sample volumes ranged from 10-360 L to achieve a sample mass of 1-5 mg per sample. The aerosol concentration was calculated from the difference between the weight of the pre-weighed filter (Sartorius M3P-000 V001 balance; Sartorius, Germany) and the weight of the filter after sampling with reference to the sample volume of the aerosol. Two samples were drawn from each exposure chamber on each exposure day (total 10 samples per concentration over the 5-day exposure period). Means and standard deviations were calculated from these 10 samples per concentration.

Aerosol particle characterization was performed with an eight-stage Cascade Impactor (Marple Personal Cascade Impactor; Sierra-Andersen, USA). The effective aerodynamic cut-off diameters were $21,15,10,6.5,3.5$, $1,0.7$, or $0.4 \mu \mathrm{m}$. A backup filter was used to collect particles smaller than $0.4 \mu \mathrm{m}$. A vacuum pump (Millipore; Merck, Darmstadt, Germany) with a flow-limiting orifice calibrated to $3 \mathrm{~L} / \mathrm{min}$ (Millipore) was used for sampling. The stages were weighed before and after sampling using 

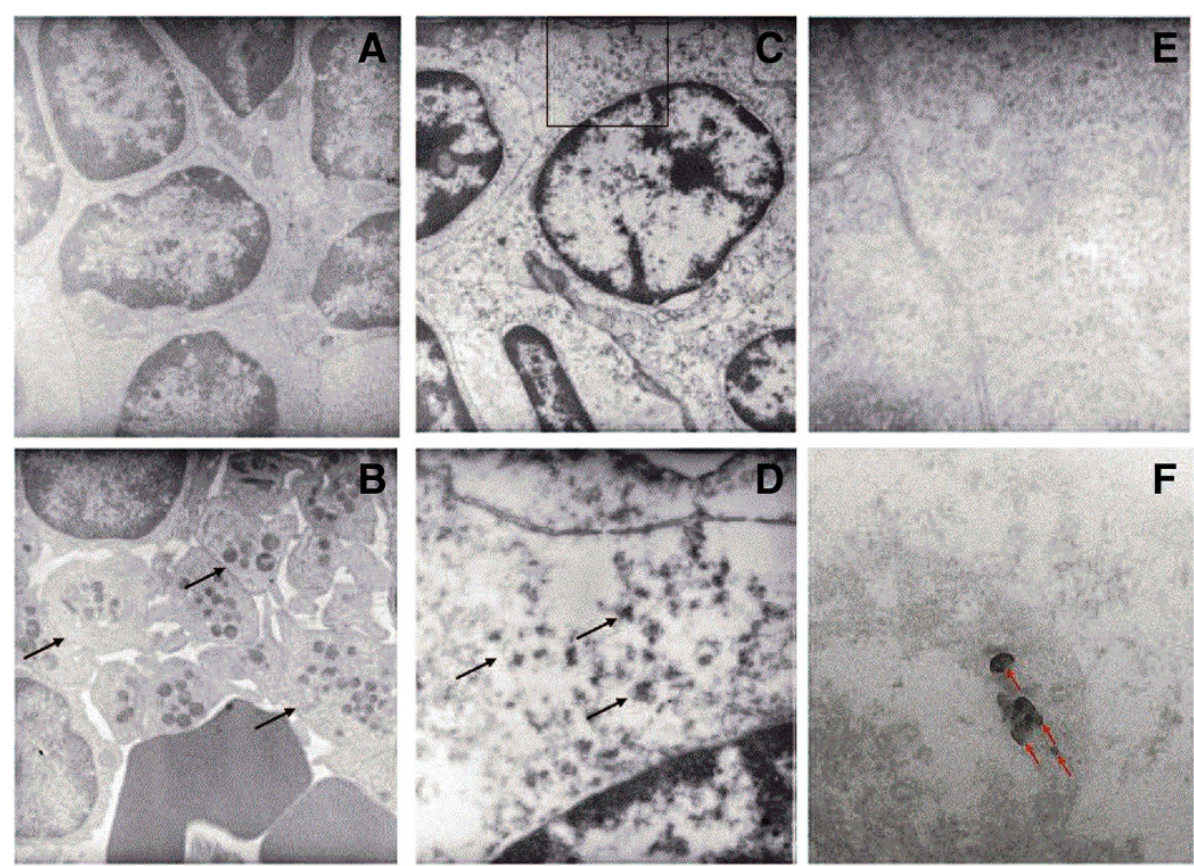

Figure 4 Transmission electron microscopy of the spleen. A: control animal, magnification 8000x; $\mathbf{B}$ : animal exposed to $10 \mathrm{mg} / \mathrm{m}^{3} \mathrm{SiO}{ }_{2}$. acrylate, magnification 8000x. Image showing accumulation of large numbers of thrombocytes (arrows); C: animal exposed to $10 \mathrm{mg} / \mathrm{m}^{3} \mathrm{SiO}$. acrylate, magnification 8000x. The lymphocytic cytoplasm is less homogenous than that of the control animal. D: magnification (25 000x) of an indicated sector of panel C, showing small electron-dense aggregates within the lymphocytic cytoplasm (arrows). E: Magnification (50 000x) of lymphocytic cytoplasm of the control animal having a very homogenous structure. $\mathbf{F}$ : Animal exposed to $10 \mathrm{mg} / \mathrm{m}^{3} \mathrm{SiO}_{2}$.acrylate, magnification 200 000x. Again, the lymphocytic cytoplasm is less homogenous than that of the control animal, and electron-dense particles are found within the cytoplasm. By EDX analysis, the electron-dense particles were identified as being silicon-rich.

a Sartorius balance (see above) or a Mettler AT 250 balance (Mettler-Toledo, Germany). Sample volumes were between $15 \mathrm{~L}$ and $720 \mathrm{~L}$ depending on their atmospheric concentration.

Additionally, particle size distribution was measured with a Scanning Mobility Particle Sizer (SMPS, model 3022A/3071A; TSI, USA). The SMPS system comprised a Model 3071A Electrostatic Classifier separating the particles into known size fractions and a model 3022A Condensation Particle Counter measuring particle count concentrations. Particles in the size range from 0.015$0.805 \mu \mathrm{m}$ were measured with 32 size channels per decade. The SMPS sampled at a frequency of $0.3 \mathrm{~L} / \mathrm{min}$, and the sheath flow was $3 \mathrm{~L} / \mathrm{min}$. At this setting, larger

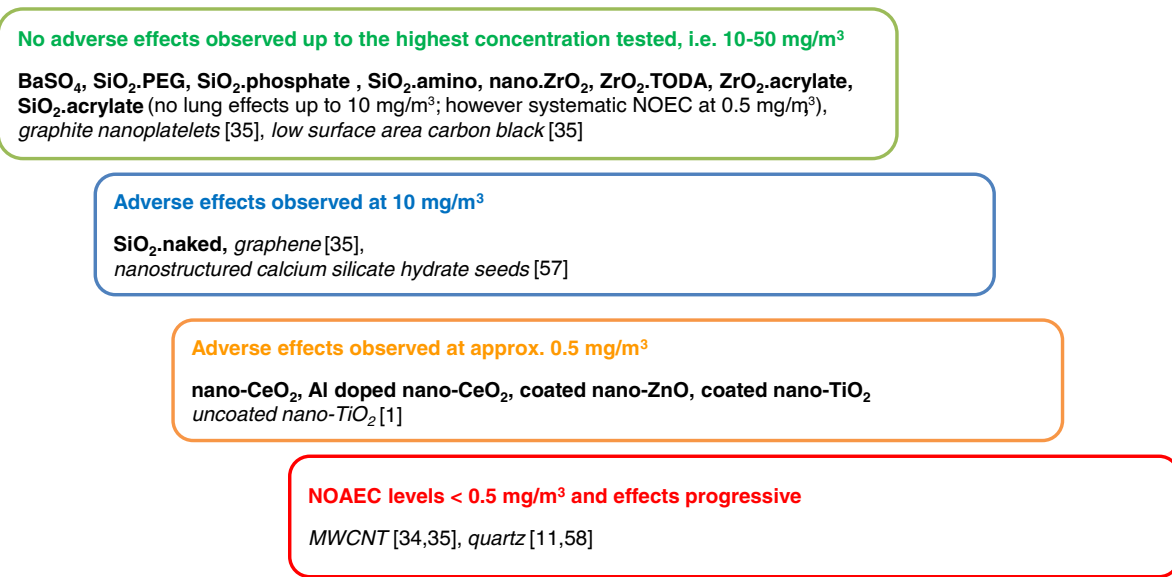

Figure 5 Ranking of nanomaterials according to their toxic potency. Names of substances presented in this paper are printed in bold. Names of substances assessed in other studies are printed in italics and the corresponding reference is provided [1,11,35,57,58]. 
particles were removed by an impactor $(0.8 \mu \mathrm{m}$ cut-off $)$ at the inlet of the SMPS.

Finally, all aerosols were measured with an aerosol spectrometer (WELAS 2000; Palas, Karlsruhe, Germany) in which single particles are illuminated with a white-light source. The measuring range of the sensor was $0.3-10 \mu \mathrm{m}$ and the sampling flow rate $5 \mathrm{~L} / \mathrm{min}$.

\section{Animals}

Permission for performance of the animal studies was obtained from the local regulatory agencies, and all protocols stood in compliance with the respective federal guidelines. Male Wistar (strain Crl:WI (Han)) rats (7 weeks of age; specific pathogen free) were obtained from Charles River Laboratories (Sulzfeld, Germany). The laboratories of BASF's Experimental Toxicology and Ecology Unit, where all studies were performed, possess an AAALAC accreditation (International Association for Assessment and Accreditation of Laboratory Animal Care). All procedures for animal care and exposure were conducted in accordance with the provisions of the German Animal Welfare Act (1998). For a few substances, the animals were housed individually in mesh-floored cages, whereas for the majority of the studies (that were performed at a later time point), social housing was applied (polysulfonate cages (H-Temp [PSU]), floor area about $2065 \mathrm{~cm}^{2}(610 \times 435 \times 215 \mathrm{~mm})$; supplied by TECHNIPLAST, Germany). All animals rooms were maintained at $20-24^{\circ} \mathrm{C}$, with a relative humidity of $30-70 \%$ and a light/ dark cycle of twelve h each. All animals were acclimatized to these conditions for about two weeks before the onset of the study. In home cages, the animals were allowed free access to laboratory diet (Provimi Kliba SA, Basel, Switzerland) and water, but not during the exposure periods.

\section{Study design}

The male Wistar rats (c.f. Table 5 for the concrete numbers of animals used for the testing of the different materials) were exposed to test substance aerosols, or conditioned air in the control groups, for six h per day on five consecutive days by head-nose exposure. 'Exposure groups' were euthanized shortly after the final exposure, and 'recovery groups' after the three-week post-exposure period (two weeks for $\mathrm{SiO}_{2}$.acrylate).

Bronchoalveolar lavage of 5 rats/test group was performed, and the BALF was analysed, determining BALF cytology, total protein, enzyme activities and (apart from the test groups treated with coated nano- $\mathrm{TiO}_{2}$ ) BALF cytokines and chemokines (described in detail in Evaluation of bronchoalveolar lavage fluid (BALF) and lung tissue homogenates). For a number of test substances, cytokines and chemokines were additionally assessed in tissue homogenates of the lavaged lungs (Evaluation of bronchoalveolar lavage fluid (BALF) and lung tissue homogenates). The blood obtained from the 5 animals/ test group used for BALF collection (again apart from coated nano- $\mathrm{TiO}_{2}$ ) was submitted to haematology and clinical chemistry in accordance with the parameters listed in OECD TG 412, and, additionally, c-reactive protein and haptoglobin were assessed (Blood analysis). Three or six animals from all test or control groups from the exposure or recovery groups were submitted to necropsy and histopathological evaluation of the respiratory tract (Necropsy and histopathological evaluation). For those test groups treated with micron-scaled or coated nano- $\mathrm{ZnO}$, nano- $\mathrm{CeO}_{2}$ or nano- $\mathrm{ZrO}_{2}$, cell proliferation and apoptosis rates were determined in the large and medium bronchi, terminal bronchioli, and alveoli (Assessment of cell proliferation and apoptosis). In those animals submitted to necropsy, organ burden was determined, i.e. the content of the test materials in the lung, in the mediastinal lymph nodes, and in the extrapulmonary organs (Organ burden analysis and TEM and EDX organ analysis). In addition, the spleens of 3 rats, each, of the highest dose group treated with $\mathrm{SiO}_{2}$.acrylate as well as of the corresponding control group were submitted to transmission electron microscopic investigation and, for one spleen, each, to EDX analysis (Organ burden analysis and TEM and EDX organ analysis).

The 13 nanomaterials and micron-scale $\mathrm{ZnO}$ were tested over a period of four years with slightly differing study designs for the different test materials (c.f. Table 5 for details on the study designs for each material and a specification of the respective examinations performed at different time points).

\section{Evaluation of bronchoalveolar lavage fluid (BALF) and lung tissue homogenates}

The animals used for BALF collection were anesthetized and exsanguinated, and the exposed lungs were washed by two instillations of physiologic saline solution (flow rate $12 \mathrm{ml} / \mathrm{min}$; instillation volumes were adjusted to the mean group body weight $(0.9 \%(\mathrm{w} / \mathrm{v}), 6-8 \mathrm{ml} / \mathrm{wash})$. About $92 \%$ of the instilled solution was recovered as lavage fluid per animal. The two washes were combined and mixed prior to analysis. Aliquots of combined BALF were used to determine total protein concentration, total cell count, differential cell count, and activities of BALF enzymes as well as mediator levels.

Total BALF cell counts were determined with an Advia 120 (Siemens Diagnostics, Fernwald, Germany) hematology analyzer. Counts of macrophages, PMN neutrophils, lymphocytes, eosinophils, monocytes and atypical cells were performed on Wright-stained cytocentrifuge slide preparations as described by [32]. The differential BALF cell count was evaluated manually by counting at least 400 cells per sample. 
The following parameters were measured with a Hitachi 917 (Roche Diagnostics, Mannheim, Germany) reaction rate analyzer:

- Total protein (turbidimetric method with Benzethonium chloride);

- Lactate dehydrogenase (EC 1.1.1.27; kinetic UV test, $340 \mathrm{~nm}, 37^{\circ} \mathrm{C}$ acc. to the International Federation of Clinical Chemistry (IFCC) reference system of enzymes);

- Alkaline phosphatase (EC 3.1.3.1; kinetic color test, $450 \mathrm{~nm}, 37^{\circ} \mathrm{C}$ acc. to IFCC);

- N-Acetyl- $\beta$-D-glucosaminidase (EC 3.2.1.30; color test, $580 \mathrm{~nm}, 37^{\circ} \mathrm{C}$; [63]);

- $\gamma$-Glutamyltransferase (EC 2.3.2.2, Szasz method (kinetic color test), $415 \mathrm{~nm}, 37^{\circ} \mathrm{C}$ acc. to IFCC).

Aiming at determining cell mediators in the BALF that were suitable in predicting substance-induced pulmonary effects, an extensive panel of altogether 68 cytokines, chemokines and inflammation-relevant hormones and enzymes were assessed in the BALF from the test groups treated with micron-scale $\mathrm{ZnO}$, coated nano- $\mathrm{ZnO}$, nano$\mathrm{CeO}_{2}$ or nano- $\mathrm{ZrO}_{2}$.

This panel of mediators comprised 67 antigens that were assessed at Rules-Based Medicine, Inc. (Austin, TX, USA) making use of the xMAP technology (Luminex Corp., Austin, TX, USA) as described previously [32,64-67]. These 67 antigens encompass the 58 antigens of the Rodent Multi-Analyte Profile (RodentMAP ${ }^{\odot}$ v. 3.0) and 9 additional antigens of the Rat KidneyMAP ${ }^{\circ}$ v. 1.0 (c.f. https://rbm.myriad.com/products-services/rodentmapservices/ for full lists of the respective panels of mediators). CINC-1, the rat homologue to IL-8, was added to this spectrum as a further, $68^{\text {th }}$ cytokine, since it had been recognized as relevant in detecting inflammatory reactions in vitro $[24,40]$. CINC-1 was measured by ELISA (Quantikine rat CINC-1, cat. no. RCN100; R\&D Systems, Inc., Minneapolis, USA).

Mediator inductions were assessed as being exposurerelated, if they were increased (1) in a concentrationdependent manner; and (2) by at least 2-fold as compared to the concurrent control value in the high dose group on one of the study days. Mediator levels that were below the respective detection limits were assessed as being unchanged.

Upon evaluation of this large panel of 68 antigens, MCP1, CINC-1, M-CSF, and OPN were determined as being most relevant for characterizing pulmonary inflammation and therefore were selected for all subsequent BALF evaluations. This restricted monitoring panel was also arranged with the aim of covering different functional groups of antigens, i.e. $\mathrm{CC}$ chemokines (MCP-1); CXC chemokines (IL-8/CINC-1); hematopoietic cytokines
(M-CSF); and inducers of proliferation of sessile cells (OPN) [1].

These four chemokines and cytokines were measured in-house using a sunrise MTP reader (Tecan AG, Switzerland) with the Magellan Software provided by the instrument producer, and making use of the following ELISA test kits:

- MCP-1 (rat MCP-1; cat. no BMS631INST; Bender MedSystems, Vienna, Austria)

- CINC-1 (Quantikine rat CINC-1, cat. no. RCN100; R\&D Systems Inc., Minneapolis, USA;);

- M-CSF (Quantikine mouse M-CSF, cat no. MMC00; R\&D Systems, Inc., Minneapolis, USA);

- OPN (Quantikine mouse OPN, cat. no. MOST00R\&D Systems, Inc., Minneapolis, USA).

In order to evaluate if antigens were washed out of pulmonary cells into the BALF, antigens were also measured directly in tissue homogenates of the lavaged lungs: After bronchoalveolar lavage, the right lung portion of each animal was resected and stored at $-80^{\circ} \mathrm{C}$ until lung tissue homogenate preparation: $0.2 \mathrm{~g}$ of the main lobe (lobus caudalis dexter) was mixed with $0.8 \mathrm{ml}$ ice-cold Tissue Protein Extraction Reagent (T-PER, cat. no. 78510, Pierce Biotechnology, Rockford, IL, USA), supplemented with Complete Protease Inhibitor Cocktail (cat no., 11873580 001, Roche, Basel, Switzerland), and homogenized for up to $40 \mathrm{~s}$ with an Ultra-Turrax (IKA, Staufen, Germany). Finally, the resulting homogenate was centrifuged at $14,000 \mathrm{~g}$ and $4^{\circ} \mathrm{C}$ for $5 \mathrm{~min}$.

Also for the mediators in the lung tissue homogenates, initial evaluations performed with lung tissues from the nano- $\mathrm{CeO}_{2}$ and nano- $\mathrm{ZrO}_{2}$ test groups aimed at determining relevant parameters, and the broad panel of 68 mediators (see above) was investigated in the samples from these test groups. The resulting comparison of mediator levels in the BALF and the lung tissue homogenates revealed that for two mediators (i.e. IL- $1 \alpha$ and TNF- $\alpha$ ), increases were consistently more pronounced in the lung tissue than in the BALF. Therefore, these two cytokines indicating local inflammation were included in the subsequent STIS (investigations of all $\mathrm{SiO}_{2}$ nanomaterials, $\mathrm{BaSO}_{4}$ and $\mathrm{Al}$-doped nano- $\left.\mathrm{CeO}_{2}\right)$. The following test kits were used:

- IL-1 $\alpha$ (FlowCytomix rat IL-1 $\alpha$ Simplex Kit; cat. no. BMS8627FF; Bender MedSystems, Vienna, Austria), measured with a FACS Calibur flow cytometer (Becton Dickinson, Heidelberg, Germany) using the instrument producer's FlowCytomix Pro Software, vs. 2.3.

- TNF- $\alpha$ (Quantikine rat TNF- $\alpha / T N F S F 1 A ;$ cat. no. RTA100R\&D Systems Inc., Minneapolis, USA), 
measured with a Sunrise MTP Reader (Tecan AG, Switzerland), using the instrument producer's Magellan Software.

\section{Blood analysis}

Blood samples from five fasted rats per dose group were collected in the mornings after overnight food withdrawal by retro-orbital venous plexus puncture under isoflurane anesthesia (Isoba ${ }^{\circ}$, Essex $\mathrm{GmbH}$; Munich, Germany). The following hematology parameters were determined in the EDTA-stabilized blood with a hematology analyzer (Advia 120, Siemens Diagnostics; Fernwald, Germany): red blood cell counts, hemoglobin, hematocrit, mean corpuscular volume (MCV), mean corpuscular hemoglobin content $(\mathrm{MCH})$, mean corpuscular hemoglobin concentration (MCHC), platelet counts, total white blood cell and differential blood cell counts.

In addition, acute phase proteins were determined in the serum:

- Haptoglobin (photometric assay based on the preservation of the hemoglobin peroxidase activity (Tridelta Ltd, Maynooth, Ireland)) was measured using the COBAS Fara instrument (Roche, Basel, Switzerland);

- C-reactive protein (ELISA; Becton Dickinson Biosciences, Heidelberg, Germany);

- $\alpha_{2}$-macroglobulin (ELISA; Kamiya Biomedical Company, Seattle, USA). The latter two were measured with a Sunrise MTP Reader (Tecan AG, Switzerland) using the Magellan Software provided by the instrument producer.

In animals exposed to micron-scale $\mathrm{ZnO}$ or coated nano $\mathrm{ZnO}$, cell mediators were also measured in serum to further assess possible systemic effects. For this purpose, samples were sent to Rules Based Medicine, Inc. (Austin, TX, USA), and the same panel of 67 antigens was measured with xMAP technology (Luminex Corporation, Austin, TX, USA), as described for the BALF samples.

\section{Necropsy and histopathological evaluation}

At necropsy, animals were exsanguinated by section of the aorta abdominalis and vena cava under Narcoren ${ }^{\circ}$ anesthesia. In accordance with the provisions of OECD TG 412, the absolute and relative organ weights of the adrenal glands, brain with olfactory bulb, epididymis, heart, kidneys, liver, lungs, spleen, testes, thymus and thyroid glands were assessed. For fixation, the lungs were instilled ( $30 \mathrm{~cm}$ water column) with neutral buffered $10 \%$ formalin (corresponding to $4 \%$ formaldehyde). Likewise, the nasal cavities (4 levels) and larynxes (3 levels) were fixed in neutral buffered $10 \%$ formalin.
The organs and tissues were trimmed and sectioned according to the trimming guides for inhalation studies [68-70]. Paraffin sections were stained with hematoxylin and eosin and examined by light microscopy. Full histopathological examinations were performed in the animals of the control and high concentration groups. If changes were observed in the high concentration, groups the respective organs and tissues of the animals exposed to the low and intermediate concentrations were also examined.

\section{Assessment of cell proliferation and apoptosis rates}

In animals exposed to $\mathrm{ZnO}$, coated nano- $\mathrm{ZnO}$, nano$\mathrm{CeO}_{2}$, and nano- $\mathrm{ZrO}_{2}$, cell proliferation and apoptosis rates were determined in large/medium bronchi, terminal bronchioli, and alveoli. Three days prior to necropsy, rats were subcutaneously implanted with Alzet osmotic pumps (Model 2ML1, Alzet Corporation; Palo Alto, CA, USA) containing $20 \mathrm{mg} / \mathrm{ml}$ 5-bromo-2-deoxyuridine (BrdU). Making use of histopathological sections that were dewaxed to remove paraffin, cell proliferation was determined after immunostaining with mouse anti-BrdU antibody (BioGene; Hamburg, Germany). Labeling indices (i.e. percentage of nuclei counted undergoing replicative DNA synthesis indicating cells present in the S-phase) were determined for three pulmonary compartments, namely the large/medium sized bronchi, the terminal bronchioli and the alveoli. In each compartment, a minimum of 1,000 cells was evaluated. Apoptosis in lung sections was determined with a TUNEL kit (Roche Diagnostics; Germany) employing the manufacturers' instructions. Counts of apoptotic cells were performed in the three pulmonary compartments mentioned above.

\section{Organ burden analysis and TEM and EDX organ analysis}

At necropsy, the lungs, the mediastinal lymph nodes, livers, kidneys, spleens as well as the basal brains with olfactory bulbs were excised. For organ burden analysis, the organs and tissues were digested, and their test material content was analysed either by Inductively Coupled Plasma-Atomic Emission Spectrometry (ICPAES, Varian Vista Pro; Palo Alto, CA, USA) or by Inductively Coupled Plasma-Mass Spectrometry (ICP-MS, Agilent 7500C; Agilent Technologies; Santa Clara, CA, USA). Sample solutions were nebulized with a Meinhard Nebulizer (Meinhard; CO, USA), and the respective main element of the given test substance ( $\mathrm{Ti}, \mathrm{Zr}, \mathrm{Si}, \mathrm{Ba}$, or $\mathrm{Ce}$ ) was analyzed at a plasma power of $1200 \mathrm{~W}$ (ICP-AES) or $1150 \mathrm{~W}$ (ICP-MS).

In addition to the analytically determined lung burden, the fraction of potential pulmonary deposition (Table 4) was calculated using the MPPD software, version 2.11 $[30,31]$. The MPPD model is based on the empirically determined mass median aerodynamic diameter (MMAD) 
and the geometric standard deviation (GSD) obtained during nose-only inhalation studies. Since the MPPD model requires indicating particle density, for all solid substances, agglomerate density, determined by $\mathrm{Hg}$ porosimetry, was applied. For all liquid substances, the material's density was included, instead. Since these materials only form small agglomerates, agglomerate density approaches their physical density.

For organ analysis by TEM and EDX analysis, animals were anesthetized with isoflurane, and perfused transcardially with cacodylate buffer (resulting in euthanasia by exsanguination) and thereafter fixed with $5 \%$ glutaraldehyde. Lungs, mediastinal lymph nodes, brain and spleen were embedded in epoxy resin. Semi-thin and ultra-thin sections of the spleen were cut from 3 control animals and 3 animals exposed to $\mathrm{SiO}_{2}$.acrylate. Sections were assessed by TEM. For one animal, each, of the control and dose groups, EDX analysis was performed to detect silicon particles on the ultra-thin section.

\section{Statistical analysis}

Substance-induced effects on body weight were assessed using Dunnett's test [71,72] by comparing each dose group with the corresponding control group. All BALF data and the serum mediator data were subjected to non-parametric one-way analysis using the KruskalWallis test (two-sided). If the resulting $\mathrm{p}$ value was 0.05 or below, a pairwise comparison of each dose group with the corresponding control group was performed using the two-sided Wilcoxon test or the two-sided MannWhitney U-test [73]. Cell proliferation and apoptosis data were analysed by pairwise comparison of each dose group with the corresponding control group using the one-sided Wilcoxon test.

\section{Additional files}

Additional file 1: Tables S1-S9. Substance-induced effects in the bronchoalveolar fluid (BALF) or lung tissue homogenates.

Additional file 2: Tables S10-S15. Summary of incidences and severities of histopathological observations in rats exposed to $\mathrm{TiO}_{2}, \mathrm{ZnO}$ and $\mathrm{CeO}_{2}$ test materials.

\footnotetext{
Abbreviations

AAN: Average agglomeration number; ALP: Alkaline phosphatase; AUC: Analytical ultracentrifugation; BALF: Bronchoalveolar lavage fluid; BET: Method of Brunauer-Emmett-Teller; CINC: Cytokine-induced neutrophil chemoattractant; CRP: C-reactive protein; $D_{50}$ : Medium value of the particle size distribution; DMEM/FCS: Dulbecco's modified eagle medium supplemented with 10\% fetal calf serum; EDX: Energy dispersed x-ray spectroscopy; EG: Exposure groups, i.e. groups of rats euthanized within 1-3 days after the final exposure; EGF: Epidermal growth factor; $\mathrm{ESR}+\mathrm{CPH}$ : Electron spin resonance making use of centrophenoxine spin traps; ESR+DMPO: Electron spin resonance making use of dimethyl-pyrrolineN-oxide spin traps; GCP: Granulocyte chemotactic peptide; GGT: YGlutamyltransferase; ICP-AES: Inductively coupled plasma atomic emission spectrometry; ICP-MS: Inductively coupled plasma optical emission spectrometry; IFCC: International federation of clinical chemistry;
}

IFN: Interferon; IP-10: Interferon inducible protein-10; IL: Interleukin; KC/GROa: Keratinocyte cytokine/Growth-regulated oncogen-a; LDH: Lactate dehydrogenase; LOQ: Limit of quantification; M-CSF: Macrophage colony stimulating factor; MCP: Monocyte chemoattractant protein;

MDC: Macrophage-derived chemoattractant; MIP: Macrophage inflammatory protein; MMAD: Mass median aerodynamic diameter; MMP: Matrix metalloproteinase; MPO: Myeloperoxidase; MPPD: Multiple-path particle dosimetry model; MWCNTs: Multi-walled carbon nanotubes; NAG: N-Acetyl- $\beta$-glucosaminidase; NGAL: Neutrophil gelatinase associated lipocalin; NO: Nitric oxide; NOAEC: No observed adverse effect concentration; NOEC: No observed effect concentration; OPN: Osteopontin;

PEG: Polyethyleneglycol; PMN: Polymorphonuclear; PPS: Primary particle size; RG: Recovery groups: i.e. groups of animals euthanized after the 14- or 21-day post-exposure recovery period; ROS: Reactive oxygen species; SEM: Scanning electron microscopy; SGD: Geometric standard deviation; SGOT: Serum glutamic oxaloacetic transaminase; SI: Supplementary information; SIMS: Secondary ion mass spectrometry; SMPS: Scanning mobility particle sizer; SWCNT: Single-walled carbon nanotubes; STIS: Short-term inhalation study protocol; TEM: Transmission electron microscopy; TIMP: Tissue inhibitor of metalloproteinases; TGF: Transforming growth factor; TNF: Tumor necrosis factor; TODA: Trioxadecanoic acid; VCAM: Vascular cellular adhesion molecule; VEGF: Vascular endothelial growth factor; VWF: Van Willebrand factor; XPS: X-ray photoelectron spectroscopy; XRD: $X$-ray diffusion.

\section{Competing interests}

RL, LM, TH, VS, ST, WW, SG, KW, BR are employees of BASF SE, a chemical company producing and marketing nanomaterials. The $\mathrm{TiO}_{2}$ and the $\mathrm{ZnO}$ test materials are or were commercialized by BASF as cosmetic sunscreens. The non-surface functionalized $\mathrm{SiO}_{2}$ nanomaterial is being used by BASF for various applications. Some of the other nanomaterials are or were evaluated during product research and development.

\section{Authors' contributions}

$\mathrm{RL}$ led the projects on inhalation toxicity of nanomaterials, and designed, monitored and assessed the studies. LM carried out the inhalation experiments. VS performed the analysis of BALF. ST, KK, and SG carried out the histopathological evaluation. WW performed the physico-chemical characterization of the materials. RL, LM, MW and TH wrote the manuscript. KW and BR advised the design and the interpretation of the results. All authors read and approved the final manuscript.

\section{Acknowledgments}

The authors wish to thank Elke Wittmer, Ernst Bohrer, Stefan Rath, Sarah Koppenhagen, Irmgard Weber, Jeanette Vogt, Vanessa Seel, Ulrich Flörchinger, Inta Kögel, Hans-Robert Hofmann, and Thomas Tatarewicz for their excellent technical assistance in performing the inhalation studies, the clinical and histopathological examinations, Lars Meyer for material characterization, and Thomas Kuhlbusch and Bryan Hellack for ESR measurements. The authors further gratefully acknowledge Ursula G. Sauer, Scientific Consultancy - Animal Welfare, for meticulously editing and proofreading the manuscript.

The work of the present study was sponsored by the German nanoCare (BMBF 03X0021C) and NanoGEM projects (BMBF 03X0105M), the European NanoSafe2 project (FP6) and by BASF SE.

\footnotetext{
Author details

'Experimental Toxicology and Ecology, BASF SE, 67056 Ludwigshafen, Germany. ${ }^{2}$ Institute for Biological Emission Evaluation, Münster, Germany. ${ }^{3}$ Material Physics, BASF SE, Ludwigshafen, Germany. ${ }^{4}$ Product Safety, BASF SE, Ludwigshafen, Germany.

Received: 10 September 2013 Accepted: 11 March 2014 Published: 4 April 2014

References

1. Ma-Hock L, Burkhardt S, Strauss V, Gamer AO, Wiench K, van Ravenzwaay B, Landsiedel R: Development of a short-term inhalation test in the rat using nano-titanium dioxide as a model substance. Inhal Toxicol 2009, 21:102-118.
} 
2. Bermudez E, Mangum JB, Wong BA, Asgharian B, Hext PM, Warheit DB, Everitt Jl: Pulmonary responses of mice, rats, and hamsters to subchronic inhalation of ultrafine titanium dioxide particles. Toxicol Sci 2004, 77:347-357.

3. Klein CL, Wiench K, Wiemann M, Ma-Hock L, van Ravenzwaay B, Landsiedel $R$ : Hazard identification of inhaled nanomaterials: making use of short-term inhalation studies. Arch Toxicol 2012, 86:1137-1151.

4. Donaldson K, Brown D, Clouter A, Duffin R, Macnee W, Renwick L, Tran L, Stone V: The pulmonary toxicology of ultrafine particles. J Aerosol Med 2002, 15:213-220.

5. Monteiller C, Tran L, Macnee W, Faux S, Jones A, Miller B, Donaldson K: The pro-inflammatory effects of low-toxicity low-solubility particles, nanoparticles and fine particles, on epithelial cells in vitro: the role of surface area. Occup Environ Med 2007, 64:609-615.

6. Oberdörster G, Ferin J, Gelein R, Soderholm SC, Finkelstein J: Role of the alveolar macrophage in lung injury: studies with ultrafine particles. Environ Health Perspect 1992, 97:193-199.

7. Bermudez E, Mangum JB, Asgharian B, Wong BA, Reverdy EE, Janszen DB, Hext PM, Warheit DB, Everitt Jl: Long-term pulmonary responses of three laboratory rodent species to subchronic inhalation of micron-scale titanium dioxide particles. Toxicol Sci 2002, 70:86-97.

8. Sayes CM, Reed KL, Warheit DB: Assessing toxicity of fine and nanoparticles: comparing in vitro measurements to in vivo pulmonary toxicity profiles. Toxicol Sci 2007, 97:163-180.

9. Cho WS, Duffin R, Poland CA, Howie SE, Macnee W, Bradley M, Megson IL, Donaldson K: Metal oxide nanoparticles induce unique inflammatory footprints in the lung: important implications for nanoparticle testing. Environ Health Perspect 2010, 118:1699-1706.

10. Merget R, Bauer T, Kupper HU, Philippou S, Bauer HD, Breitstadt R, Bruening T: Health hazards due to the inhalation of amorphous silica. Arch Toxicol 2002, 75:625-634.

11. Johnston CJ, Driscoll KE, Finkelstein JN, Baggs R, O'Reilly MA, Carter J, Gelein $\mathrm{R}$, Oberdörster $\mathrm{G}$ : Pulmonary chemokine and mutagenic responses in rats after subchronic inhalation of amorphous and crystalline silica. Toxicol Sci 2000, 56:405-413.

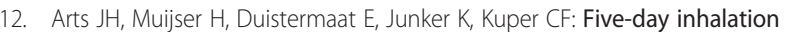
toxicity study of three types of synthetic amorphous silicas in Wistar rats and post-exposure evaluations for up to 3 months. Food Chem Toxicol 2007, 45:1856-1867.

13. Tran CL, Buchanan D, Cullen RT, Searl A, Jones AD, Donaldson K: Inhalation of poorly soluble particles. II. Influence of particle surface area on inflammation and clearance. Inhal Toxicol 2000, 12:1113-1126.

14. Pott F, Roller M: Carcinogenicity study with nineteen granular dusts in rats. Eur J Oncol 2005, 10:249-281.

15. Srinivas A, Rao PJ, Selvam G, Murthy PB, Reddy PN: Acute inhalation toxicity of cerium oxide nanoparticles in rats. Toxicol Lett 2011, 205:105-115.

16. Ma JY, Zhao H, Mercer RR, Barger M, Rao M, Meighan T, Schwegler-Berry D, Castranova V, Ma JK: Cerium oxide nanoparticle-induced pulmonary inflammation and alveolar macrophage functional change in rats. Nanotoxicol 2011, 5:312-325.

17. Toya T, Takata A, Otaki N, Takaya M, Serita F, Yoshida K, Kohyama N: Pulmonary toxicity induced by intratracheal instillation of coarse and fine particles of cerium dioxide in male rats. Ind Health 2010, 48:3-11.

18. McDonald JW, Ghio AJ, Sheehan CE, Bernhardt PF, Roggli VL: Rare earth (cerium oxide) pneumoconiosis: analytical scanning electron microscopy and literature review. Mod Pathol 1995, 8:859-865.

19. Valberg PA, Bruch J, McCunney RJ: Are rat results from intratracheal instillation of 19 granular dusts a reliable basis for predicting cancer risk? Regul Toxicol Pharmacol 2009, 54:72-83.

20. Hartwig A: Gesundheitsschädliche Arbeitsstoffe. Toxikologischarbeitsmedizinische Begründung von MAK-Werten. Weinheim: VCH Verlagsgesellschaft; 2013.

21. German Federal Ministry of Labour and Social Affairs (BMAS; Bundesministerium für Arbeit und Soziales): Bekanntmachung von technischen Regeln. (Notice of technical provisions). TRGS 900 Arbeitsplatzgrenzwerte (Workplace limits); 2014. Notice IIIb 3 - 35125 - 5 of the BMAS.

22. Wohlleben W, Ma-Hock L, Boyko V, Cox G, Egenolf $H$, Freiberger $H$, Hinrichsen B, Hirth S, Landsiedel R: Nanospecific guidance in REACH: a comparative physicalchemical characterization of 15 materials with methodical correlations. J Ceramic Sci Technol 2013, 4:93-104.
23. Hellack B, Hülser T, Izak E, Kuhlbusch T, Meyer F, Spree M, Voetz M, Wiggers $\mathrm{H}$, Wohlleben W: Characterization report for all nanoGEM materials. Frankfurt: Dechema eV; 2009.

24. Sauer UG, Vogel S, Aumann A, Hess A, Kolle SN, Ma-Hock L, Wohlleben W, Dammann M, Strauss V, Treumann S, Groters S, Wiench K, van Ravenzwaay B, Landsiedel R: Applicability of rat precision-cut lung slices in evaluating nanomaterial cytotoxicity, apoptosis, oxidative stress, and inflammation. Toxicol Appl Pharmacol 2013: . epub ahead of print.

25. Kuhlbusch THJ, Krug HF, Nau K: Nanocare - Health related effects of nanoparticles. Final scientific report. Frankfurt: Dechema eV; 2009.

26. Cullen RT, Tran CL, Buchanan D, Davis JM, Searl A, Jones AD, Donaldson K: Inhalation of poorly soluble particles. I. Differences in inflammatory response and clearance during exposure. Inhal Toxicol 2000, 12:1089-1111.

27. van Ravenzwaay B, Landsiedel R, Fabian E, Burkhardt S, Strauss V, Ma-Hock $L$ : Comparing fate and effects of three particles of different surface properties: nano- $\mathrm{TiO}_{2}$, micron-scale $\mathrm{TiO}_{2}$ and quartz. Toxicol Lett 2009, 186:152-159.

28. Hadjimichael OC, Brubaker RE: Evaluation of an occupational respiratory exposure to a zirconium-containing dust. J Occup Med 1981, 23:543-547.

29. Marcus RL, Turner S, Cherry NM: A study of lung function and chest radiographs in men exposed to zirconium compounds. Occup Med (Lond) 1996, 46:109-113.

30. Anjilvel S, Asgharian B: A multiple-path model of particle deposition in the rat lung. Fundam Appl Toxicol 1995, 28:41-50.

31. RIVM (Netherlands National Institute for Public Health and the Environment): Multiple Path Particle Dosimetry Model (MPPD v 1.0): A Model for Human and Rat Airway Particle Dosimetry. Bilthoven, The Netherlands: RIVA Report 650010030; 2002

32. Warheit DB, Hartsky MA: Role of alveolar macrophage chemotaxis and phagocytosis in pulmonary clearance responses to inhaled particles: comparisons among rodent species. Microsc Res Tech 1993, 26:412-422.

33. Zhou J, Xu N, Wang ZL: Dissolving behavior and stability of ZnO wires in biofluids: a study on biodegradability and biocompatibility of $\mathrm{ZnO}$ nanostructures. Adv Mater 2006, 18:2432-2435.

34. Ma-Hock L, Treumann S, Strauss V, Brill S, Luizi F, Mertler M, Wiench K, Gamer AO, van Ravenzwaay B, Landsiedel R: Inhalation toxicity of multiwall carbon nanotubes in rats exposed for 3 months. Toxicol Sci 2009, 112:468-481.

35. Ma-Hock L, Strauss V, Treumann S, Küttler K, Wohlleben W, Hofmann T, Gröters S, Wiench K, van Ravenzwaay B, Landsiedel R: Comparative inhalation toxicity of multi-wall carbon nanotubes, graphene, graphite nanoplatelets and low surface carbon black. Part Fibre Toxicol 2013, 10:23.

36. Ma-Hock L, Brill S, Wohlleben W, Farias PMA, Chaves CR, Tenório DPLA, Fontes A, Santos BS, Landsiedel R, Strauss V, Treumann S, van Ravenzwaay $B$ : Short term inhalation toxicity of a liquid aerosol of $\mathrm{CdS} / \mathrm{Cd}(\mathrm{OH})_{2}$ core shell quantum dots in male Wistar rats. Toxicol Lett 2012, 208:115-124.

37. Ma-Hock L, Farias PMA, Hofmann T, Andrade ACDS, Silva JN, Arnaud TMS, Wohlleben W, Strauss V, Treumann S, Chaves CRS, Gröters S, Landsiedel R, van Ravenzwaay B: Short term inhalation toxicity of a liquid aerosol of glutaraldehyde-coated $\mathrm{CdS} / \mathrm{Cd}(\mathrm{OH})_{2}$ core shell quantum dots in rats. Toxicol Lett 2014, 225:20-26.

38. Ma-Hock L, Landsiedel R, Wiench K, Geiger D, Strauss V, Gröters S, van Ravenzwaay B, Gerst M, Wohlleben W, Scherer G: Short-term rat inhalation study with aerosols of acrylic ester-based polymer dispersions containing a fraction of nanoparticles. Int J Toxicol 2012, 31:46-57.

39. Maus U, Herold S, Muth H, Maus R, Ermert L, Ermert M, Weissmann N, Rosseau S, Seeger W, Grimminger F, Lohmeyer J: Monocytes recruited into the alveolar air space of mice show a monocytic phenotype but upregulate CD14. Am J Physiol Lung Cell Mol Physiol 2001, 280:L58-L68.

40. Donaldson K, Borm PJ, Oberdörster G, Pinkerton KE, Stone V, Tran CL: Concordance between in vitro and in vivo dosimetry in the proinflammatory effects of low-toxicity, low-solubility particles: the key role of the proximal alveolar region. Inhal Toxicol 2008, 20:53-62.

41. Abbas AK, Lichtman AH, Pober JS: Cellular and molecular immunology. Philadelphia, USA: W.B. Saunders Company; 1997.

42. Matsunaga I, Oka S, Fujiwara N, Yano I: Relationship between induction of macrophage chemotactic factors and formation of granulomas caused by mycoloyl glycolipids from Rhodococcus ruber (Nocardia rubra). J Biochem 1996, 120:663-670. 
43. Denhardt DT, Guo X: Osteopontin: a protein with diverse functions. FASEB J 1993, 7:1475-1482.

44. Scott JA, Weir ML, Wilson SM, Xuan JW, Chambers AF, McCormack DG Osteopontin inhibits inducible nitric oxide synthase activity in rat vascular tissue. Am J Physiol 1998, 275:H2258-H2265.

45. Chiba S, Rashid MM, Okamoto H, Shiraiwa H, Kon S, Maeda M, Murakami M, Inobe M, Kitabatake A, Chambers AF, Uede T: The role of osteopontin in the development of granulomatous lesions in lung. Microbiol Immunol 2000, 44:319-332.

46. O'Regan AW, Hayden JM, Body S, Liaw L, Mulligan N, Goetschkes M, Berman JS: Abnormal pulmonary granuloma formation in osteopontin-deficient mice. Am J Respir Crit Care Med 2001, 164:2243-2247.

47. Mangum J, Bermudez E, Sar M, Everitt J: Osteopontin expression in particle-induced lung disease. Exp Lung Res 2004, 30:585-598.

48. Driscoll KE, Hassenbein DG, Carter JM, Kunkel SL, Quinlan TR, Mossman BT: TNF alpha and increased chemokine expression in rat lung after particle exposure. Toxicol Lett 1995, 82-83:483-489.

49. Driscoll KE, Carter JM, Howard BW, Hassenbein DG, Pepelko W, Baggs RB, Oberdörster G: Pulmonary inflammatory, chemokine, and mutagenic responses in rats after subchronic inhalation of Carbon Black. Toxicol Appl Pharmacol 1995, 136:372-380.

50. Ishii H, Fujii T, Hogg JC, Hayashi S, Mukae H, Vincent R, van Eeden SF: Contribution of IL-1 beta and TNF-alpha to the initiation of the peripheral lung response to atmospheric particulates (PM10). Am J Physiol Lung Cell Mol Physiol 2004, 287:L176-L183.

51. Beutler BA: The role of tumor necrosis factor in health and disease. J Rheumatol Supp/ 1999, 57:16-21.

52. Lukacs NW, Strieter RM, Chensue SW, Widmer M, Kunkel SL: TNF-alpha mediates recruitment of polymorphonuclear neutrophils and eosinophils during airway inflammation. J Immunol 1995, 154:5411-5417.

53. Rehn B, Bruch J, Zou T, Hobusch G: Recovery of rat alveolar macrophages by bronchoalveolar lavage under normal and activated conditions. Environ Health Perspect 1992, 97:11-16.

54. ILSI Risk Science Institute Workshop Participants: The relevance of the rat lung response to particle overload for human risk assessment: a workshop consensus report. Inhal Toxicol 2000, 12:1-17.

55. Oomen AG, Bos PM, Fernandes TF, Hund-Rinke K, Boraschi D, Byrne HJ, Aschberger K, Gottardo S, von der Kammer F, Kuhnel D, Hristozov D, Marcomini A, Migliore L, Scott-Fordsmand J, Wick P, Landsiedel R: Concern-driven integrated approaches to nanomaterial testing and assessment - report of the NanoSafety Cluster Working Group 10. Nanotoxicol 2014, 8:334-348.

56. Pauluhn J: Subchronic 13-week inhalation exposure of rats to multiwalled carbon nanotubes: toxic effects are determined by density of agglomerate structures, not fibrillar structures. Toxicol Sci 2010, 113:226-242.

57. Bräu M, Ma-Hock L, Hesse C, Nicoleau L, Strauss V, Treumann S, Wiench K, Landsiedel R, Wohlleben W: Nanostructured calcium silicate hydrate seeds accelerate concrete hardening: a combined assessment of benefits and risks. Arch Toxicol 2012, 86:1077-1087.

58. Muhle H, Kittel B, Ernst H, Mohr U, Mermelstein R: Neoplastic lung lesions in rat after chronic exposure to crystalline silica. Scand J Work Environ Health 1995, 21(Suppl 2):27-29.

59. Kuempel ED, Castranova V, Geraci CL, Schulte PA: Development of risk-based nanomaterial groups for occupational exposure control. J Nanopart Res 2012, 14:1029-1043.

60. Russell WMS, Burch RL: The principles of humane experimental technique. London, UK: Methuen; 1959. Reprinted by UFAW, 1992: 8 Hamilton Close, South Mimms, Potters Bar, UK.

61. Directive 2010/63/EU of the European Parliament and of the Council of 22 September 2010 on the protection of animals used for scientific purposes. OJ 2010, L 276:33-79. available at: http://eur-lex.europa.eu/ legalcontent/EN/TXT/?qid=1396877936469\&uri=CELEX:32010L0063.

62. Ma-Hock L, Gamer AO, Landsiedel R, Leibold E, Frechen T, Sens B, Linsenbuehler M, van Ravenzwaay B: Generation and characterization of test atmospheres with nanomaterials. Inhal Toxicol 2007, 19:833-848.

63. Yakata M, Sugita O, Sakai T, Uchiyama K, Wada K: Urinary enzyme determination and its clinical significance $C$. Enzyme derived from the kidney tubular epithelium-N-acetyl-beta-D-glucosaminidase. 4. Preclinical evaluation of the urinary NAG activity and changes in renal diseases. Rinsho Byori 1983, 56:90-101.
64. Kettman JR, Davies T, Chandler D, Oliver KG, Fulton RJ: Classification and properties of 64 multiplexed microsphere sets. Cytometry 1998, 33:234-243

65. Elshal MF, McCoy JP: Multiplex bead array assays: performance evaluation and comparison of sensitivity to ELISA. Methods 2006, 38:317-323.

66. Fulton RJ, McDade RL, Smith PL, Kienker LJ, Kettman JR Jr: Advanced multiplexed analysis with the FlowMetrix system. Clin Chem 1997, 43:1749-1756.

67. Skogstrand K, Thorsen P, Norgaard-Pedersen B, Schendel DE, Sorensen LC, Hougaard DM: Simultaneous measurement of 25 inflammatory markers and neurotrophins in neonatal dried blood spots by immunoassay with xMAP technology. Clin Chem 2005, 51:1854-1866.

68. Ruehl-Fehlert C, Kittel B, Morawietz G, Deslex P, Keenan C, Mahrt CR, Nolte $T$, Robinson M, Stuart BP, Deschl U: Revised guides for organ sampling and trimming in rats and mice - part 1. Exp Toxicol Pathol 2003, 55:91-106.

69. Kittel B, Ruehl-Fehlert C, Morawietz G, Klapwijk J, Elwell MR, Lenz B, O'Sullivan MG, Roth DR, Wadsworth PF: Revised guides for organ sampling and trimming in rats and mice - part 2. A joint publication of the RITA and NACAD groups. Exp Toxicol Pathol 2004, 55:413-431.

70. Morawietz G, Ruehl-Fehlert C, Kittel B, Bube A, Keane K, Halm S, Heuser A, Hellmann J: Revised guides for organ sampling and trimming in rats and mice - part 3. A joint publication of the RITA and NACAD groups. Exp Toxicol Pathol 2004, 55:433-449.

71. Dunnett CW: A multiple comparison procedure for comparing several treatments with a control. JASA 1955, 50:1096-1121.

72. Dunnett CW: New tables for multiple comparisons with a control. Biometrics 1964, 20:482-491.

73. Siegel S: Non-parametric statistics for the behavioural sciences. New York: McGraw-Hill; 1956.

\section{doi:10.1186/1743-8977-11-16}

Cite this article as: Landsiedel et al:: Application of short-term inhalation studies to assess the inhalation toxicity of nanomaterials. Particle and Fibre Toxicology 2014 11:16.

\section{Submit your next manuscript to BioMed Central and take full advantage of:}

- Convenient online submission

- Thorough peer review

- No space constraints or color figure charges

- Immediate publication on acceptance

- Inclusion in PubMed, CAS, Scopus and Google Scholar

- Research which is freely available for redistribution

Submit your manuscript at www.biomedcentral.com/submit
C Biomed Central 